Article

\title{
Exploring Domestic Precycling Behavior: A Social Identity Perspective
}

\author{
Klara Wenzel *(D) and Elisabeth Süßbauer \\ Center for Technology and Society, Technische Universität Berlin, 10553 Berlin, Germany; \\ suessbauer@ztg.tu-berlin.de \\ * Correspondence: wenzel@ztg.tu-berlin.de
}

check for

updates

Citation: Wenzel, K.; Süßbauer, E. Exploring Domestic Precycling Behavior: A Social Identity Perspective. Sustainability 2021, 13, 1321. https://doi.org/10.3390/ su13031321

Received: 18 December 2020

Accepted: 22 January 2021

Published: 27 January 2021

Publisher's Note: MDPI stays neutral with regard to jurisdictional claims in published maps and institutional affiliations.

Copyright: (c) 2021 by the authors. Licensee MDPI, Basel, Switzerland. This article is an open access article distributed under the terms and conditions of the Creative Commons Attribution (CC BY) license (https:/ / creativecommons.org/licenses/by/ $4.0 /)$.

\begin{abstract}
Increasing amounts of disposable food packaging waste are contributing towards a global environmental crisis, and approaches to successfully preventing such waste-called precycling-are urgently needed. The human ability to define oneself as a member of a group (social identity) may represent a powerful source for realizing environmental endeavors. Therefore, in this article we conceptualize precycling behavior in households as pro-environmental behavior embedded in social identity processes. To explore precycling, we combined food diaries and qualitative virtual interviews with 26 households in Berlin, Germany. We analyzed our data based on the Social Identity Model of Pro-Environmental Action (SIMPEA). Starting from the behavioral element of the model (response), we substantiate the concept of precycling suggesting that it can be distinguished into six types of behavior. Furthermore, we propose that the enactment of these precycling behaviors is shaped by social identity processes and social influence in different groups, including: the household itself, neighbors, family and friends, or food collectives. We conclude that these processes are important to realizing precycling in small and private groups as well as in larger collectives. Implications are derived for empirical research and theoretical development as well as for public programs and intervention studies.
\end{abstract}

Keywords: precycling; packaging prevention; pro-environmental behavior; social identity; SIMPEA; households; waste crisis

\section{Introduction}

The current practices associated with producing and using packaging in the food sector put ecosystems under pressure in two primary ways. First, they contribute towards excessive extraction of natural resources. Second, waste from packaging poses a threat to the environment, climate and health [1-4]. Moreover, the outbreak of COVID-19 has even exacerbated the waste crisis, as the amount of single-use food packaging has increased even more during the global pandemic, due, for example, to augmented takeaway consumption and e-commerce $[5,6]$.

Political actors and regular citizens around the world are increasingly assessing growing waste as a global environmental problem and recognizing the need to take action. Most Germans, for example, rate packaging reduction as an important topic [7], and a great majority of them (87\%) also want more options for purchasing unpackaged food [8]. Additionally, about two-thirds (68\%) of them also acknowledge their own capacity for taking action to reduce packaging [8]. Meanwhile, the problem is also being addressed on different levels and with different strategies, such as via international political efforts $[9,10]$ or consumer-oriented information and awareness campaigns [11].

Nevertheless, the amount of waste from packaging is constantly increasing [12], a great portion of which stems from private end consumers. In Germany, for example, private end consumers produce around nine million tons of it per year, which is $47 \%$ of total national packaging waste [13] (p. 46). To find solutions to the waste problem, it would thus seem 
necessary to consider practices at the household level. Although recycling behavior among households has received much attention in empirical psychological studies [14], research on prevention behaviors appears even more important for countering waste generation. However, although studies on waste prevention behaviors regularly address household waste in general [15-19], there is a lack of empirical understanding regarding prevention of packaging waste in households, also called precycling behavior.

Coined originally in 1988 by Maureen O'Rorke for a public waste education campaign $[20,21]$, the concept of precycling is now employed in different contexts and academic disciplines. Greyson [22] (p. 1384), for example, defines precycling as "actions taken now to prepare for current resources to become future resources, rather than wastes accumulating in the biosphere". According to Greyson, such actions can be taken by a wide range of actors, including households, local authorities, retailers, businesses and industry, while seeking to create social, environmental, economic, and industrial conditions for preventing resource loss. Meanwhile, Klug [23] (pp. 60-64) uses the term precycling to describe behavioral strategies adopted by households to prevent waste, which differ in terms of their degrees of complexity and success in waste prevention: from small individual actions (e.g., refusing a plastic bag or over-packaging) to more complex behaviors that require detailed planning (e.g., buying loose vegetables on the market, from local producers or engaging in self-production). In contrast to the term waste prevention behavior, which targets any type of waste generated by households (e.g., electronics, textiles), the term precycling behavior is specifically related to waste from packaging of (fast moving) consumer goods, such as food or drugstore items [23]. However, in comparison to Klug, in studying precycling we do not exclusively focus on behaviors undertaken by environmentally conscious people as part of a movement or a specific lifestyle but, rather, behaviors implemented in "ordinary" households realized by one or more persons aiming to prevent food packaging waste, similarly to the concept of waste prevention behaviors but with a narrower scope.

Most research on waste prevention focuses on the individual level; yet this does not seem to adequately reflect the reality of humans as social beings who live and act together. Hence, we propose to conceptualize food packaging prevention behaviors in households as activities which are embedded within social identity processes and ingrouplevel activities. To explore this angle, we adopted a qualitative, multi-method approach to conduct a combined diary and interview study with 26 households in Berlin, Germany. The diaries and semi-structured interviews have been analyzed according to the Social Identity Model of Pro-Environmental Action (SIMPEA) [24], which is rooted in Social Identity Theory (SIT) [25]. From our perspective, SIMPEA is a suitable framework for this kind of research, as it addresses both public- and private-sphere behaviors and can be applied to any self-relevant ingroup (e.g., household, neighborhood, or workplace). Our paper aims to contribute towards an empirical foundation for the SIMPEA model, taking domestic precycling behavior as one example of pro-environmental action.

The present article is structured as follows. First, Section 1.1 presents previous studies from a growing body of research that is applying group-level and social identity approaches to investigate resource-conservation practices and domestic waste-prevention behaviors. Section 1.2 outlines our conceptual framework, based on the SIMPEA [24] and poses our research questions. Meanwhile, Section 2 describes our methods and procedures, whereas Section 3 presents our results. Section 4 discusses these results, addresses limitations of the study, and derives theoretical and practical implications of our research, while Section 5 articulates our conclusions.

\subsection{Perspectives on Household Waste Prevention: From the Individual to the Group Level}

Thus far, most empirical studies on waste prevention behavior have applied individually focused theories, such as the Theory of Planned Behavior [26], and investigated individual factors such as knowledge, personal costs and benefits, personal motives, subjective norms, values, intentions, and individual behaviors and habits [11,15,17,27-34]. Although "individuals are seen as decisive" in political and societal discourse on reducing 
resource consumption, exclusive focus on individual activities has been deemed a barrier to deeper understanding [35] (p. 6), as finding practical solutions to highly complex challenges often exceeds the scope of individual action. In this vein, Tucker and Douglas argue that the key issue related to packaging waste is that "many people feel powerless as individuals to do anything about it, even if they accept a share of the responsibility for it" [34] (p. 11). Moreover, the prevention of packaging can include complex and interrelated behaviors [17].

A recent study by Fuentes and colleagues on packaging-free shopping has even noted that the practice of shopping itself "must be reinvented" to successfully eliminate most packaging [36] (p. 258). Consequently, they suggest a "re-skilling" of the consumerdeveloping new shopping competencies-and a "re-framing" of the practice of shopping through making it meaningful in new ways [36] (p. 264). Further, household waste prevention, especially in the field of nutrition, affects many aspects of daily household organization, including social interaction and coordination and, thus, requires complex planning and behaviors for the various phases involved (e.g., purchasing food and beverages, preparation, consumption), changes in existing packaging-intensive routines, practical knowledge and other artefacts, such as reusable containers, space, availability, and access to unpackaged food $[31,37,38]$. Conceptualizing household waste prevention as an individual act disregards the fact that many people live in groups of various sizes, interacting with and influencing each other in terms of resource consumption. Such "misalignment" of relevant levels of analysis in the context of resource consumption could lead to biased results and conclusions [39] (p. 1). In this respect, studies have revealed that individuallevel predictors are relatively weak with regard to household waste prevention behaviors such as recycling or household food waste $[14,40]$. Such results highlight the need to address group-level factors in households [39] (p. 3). Hence, household-level resource consumption and conservation could be conceptualized as an "emergent property" or "outcome" of a given group-influenced by interactions and interdependences between the group members [39] (p. 3). Consequently, precycling in households should not only be seen in terms of individual behavior, realized by one person, but also group-level or collective behavior involving other people as well.

Currently, research on group-level factors and social identity is providing promising approaches towards envisioning how waste prevention can be examined. Some studies addressing group-related factors and behavior in the field of waste prevention suggest that social factors significantly influence waste prevention behavior in households, as detailed in the following paragraphs.

First, a waste reduction program in the UK analyzed small-group interventions as a way of breaking undesired habits and helping people to develop new ones [41], revealing small-group approaches as effective means towards achieving noticeable behavioral change and reductions in waste. According to the authors, two key factors determined the effectiveness of the program's approach, namely, support from like-minded others that arose from working in groups and sharing of information and advice within groups.

Second, the EcoTeam Program implemented an intervention package to bring about durable change across a range of household behaviors [42]. This team-approach program resulted in savings of $32 \%$ in waste deposition through a combination of information, feedback and social interaction within groups. For participants who reported strong social influence from their team members, social interaction with them resulted in intentions which were predictive of pro-environmental behavioral change, even for ingrained habits.

Third, a qualitative study on consumer waste and disposal behavior explored strategies and behaviors in environmentally conscious communities in the UK who have adopted a holistic approach to waste reduction [43]. Their results show that some waste prevention strategies in the community, such as repairing things, were only likely to be realized if implemented collectively, unless facilitating institutional structures were to become accessible. 
Fourth, a meta-analysis integrating 29 studies has confirmed that social influence approaches effectively encourage resource conservation behavior, including waste-reducing behaviors such as recycling and composting [44]. Interestingly, the results of this metaanalysis indicate that social influence approaches are equally effective for addressing easily observable behaviors as well as those which are more difficult to observe. According to the authors, this highlights the potential for encouraging a spectrum of pro-environmental behaviors via social influence. The authors assume the approach to be more effective in groups where social interaction is more prevalent (e.g., in households) and, furthermore, hypothesize that the effect of social influence on behavior could be moderated by group identification, arguing that personal communication and interaction might make social norms and group identity more salient which, in turn, could guide revised or new behaviors. However, they did not test their hypothesis but, rather, have called for further research on such relationships.

Fifth, another meta-analysis has evaluated behavioral interventions to promote household action aimed at reducing climate change, such as waste prevention and recycling [45]. The authors explicate that such interventions are based upon principles of social influence and social comparison and provide, for example, a "comparative reference" with respect to the pro-environmental behaviors of socially close others, including neighbors, colleagues or friends (p. 3). Their analysis reveals that social comparison messages can be considered one of the "most promising types of intervention" in this context (p. 2).

Sixth, in 2019 a meta-analysis of field-experiments including 91 field-experiments revealed a positive main effect of social norms on pro-environmental behaviors (such as waste prevention, recycling, prevention of littering) compared to no-treatment control conditions [46]. One result from their analyses indicates that implicitly induced social norms were more influential than explicitly induced social norms (p. 15). Overall, the authors conclude that these results provide strong evidence that social norms-based intervention represent a powerful method to promote pro-environmental behavioral change.

Seventh, Reese and Junge [47] have argued that individual contributions to waste reduction are generally quite limited, if not carried out by many. In a study combing a field experiment and survey regarding plastic reduction, they investigate some underlying mechanisms and predictors of collective pro-environmental action. Among other conclusions, their results suggest that collective efficacy beliefs may be particularly relevant for attaining environmental goals of moderate difficulty.

Overall, the insights from the above-presented studies imply that group-level factors can significantly influence waste prevention behavior in households. Moreover, these studies show that social influence approaches are equally effective for revealing both readily observable as well as more difficult to discern behaviors. This is important in the context of waste prevention behavior, since it is regarded as difficult to change due to its relative invisibility $[17,34]$. Social identity processes seem to contribute to the success of social influence approaches (e.g., identification with and influence of peer groups, ingroup norms, interaction, collective behavior). Especially in relatively small groups (e.g., households), personal communication and social interaction seem to be central for building group identity and norms which, in turn-depending on the nature of the shared rules and standards-could stimulate joint efforts to behave in pro-environmental ways, such by precycling.

However, in most of these studies the underlying group-related factors and processes that might determine reduction behaviors were not analyzed systematically and remain unclear. Applying a social identity perspective seems promising for examine the interrelationships between these factors.

Hence, in the next section, we present the Social Identity Model of Pro-Environmental Action (SIMPEA) [24], which we believe can help to provide answers to the above-outlined research gaps. Our study employs SIMPEA as a conceptual framework for understanding household precycling behavior. 


\subsection{Theory, Conceptual Framework, and Research Questions}

The Social Identity Model of Pro-Environmental Action (SIMPEA) [24] is rooted in the Social Identity Approach, which unifies Social Identity Theory (SIT) [25] and SelfCategorization Theory (SCT) [48]. According to SIT, individuals derive part of their selfconcept from their knowledge of and emotional attachment to groups, forming their social identity [25] (p. 63). Social group memberships can include large-scale social categories (e.g., gender), self-chosen groups (e.g., neighborhood or a flat-sharing communities), or interest-based groups (e.g., food sharing groups) [49] (p. 2). The SCT complements SIT by theorizing the social identity process of ingroup identification through selfcategorization, based upon the capacity of humans to define themselves and others in terms of personal identity ("I") and social identity ("we") [24] (p. 245). According to SCT, in the process of self-categorization, people define themselves and others in terms of membership in a group - the ingroup. Ingroup identification is the result of both self-categorization as a member of a given group and ascription of positive "emotional significance" [25] (p. 63) to this group (e.g., being proud to be part of a particular neighborhood). Often, social identities emerge from "inter-individual interactions and discussions about common opinions and actions" [24] (p. 248) [50,51]. The social identity approach proposes: When a particular group membership is salient (i.e., accessible to a person), individuals define themselves through their shared group membership and orient their attitudes and behavior towards shared group norms and motives, which they assimilate. By this means, defining the self in terms of "we" enables people to "think and act as collectives, which should be crucial given personal insufficiency to appraise and effectively respond to environmental crises" [24] (p. 245).

Taking a step further, SIMPEA brings these theoretical assumptions to bear on proenvironmental behavior, systematically outlining how appraisal and responses to environmental crises (e.g., packaging waste) are related to social identity processes. The model consists of the following elements, which can be applied to studying domestic precycling behavior:

Appraisal: As outlined above, the sheer amount of packaging waste being generated today poses a multi-level and complex threat to ecosystems and humans, and this collective crisis is now being appraised as a global problem by many people.

Response: According to SIMPEA, a response stands for a pro-environmental behavior or action to counteract an environmental crisis, either individually or collectively. Collective behavior is defined as "any group-based behavior" or action-private or publicperformed by "any salient ingroup" [24] (p. 251). In our study, the term group describes "two or more individuals who are connected by and within social relationships" [52] (p. 3). Here, we are interested in examining precycling behavior, which represents a proenvironmental response to counteract the ongoing packaging waste crisis.

SIMPEA proposes three central social identity processes that can help predict the appraisal of a crisis and responses: identification with relevant social groups, ingroup norms and goals and collective efficacy beliefs. These core factors are assumed to interact with each other and to determine whether a pro-environmental response is likely to be realized or not. Personal and collective emotions and motivations are proposed to drive these processes.

Ingroup identification: According to the authors, SIMPEA can be applied to different social levels and forms of ingroup identification, meaning any self-relevant ingroup, such as a household, neighborhood, or workplace. Being embedded in a social context and identifying oneself as a member of a positively evaluated group can influence behavioral responses-in our case, precycling.

Ingroup norms and goals: With ingroup norms, we refer to shared rules and standards in a group that represent individuals' basic knowledge of what others do (descriptive norms) and think that they should do (injunctive norms) [53] (p. 1015), e.g., thinking that precycling is important and should be undertaken by one's household group. 
Collective efficacy beliefs: Collective efficacy beliefs represent the confidence that one's own group is capable of affecting important aspects of the environment and that group goals can be achieved [54,55], e.g., buying loose vegetables to prevent packaging waste.

Emotions and motives: According to the model, emotions and motivations arise from environmental crisis appraisal and mediate the effects of such appraisal on the group-based social identity processes described above. For example, experiencing consequences of the human-generated packaging waste crisis can evoke emotions of collective guilt which, in turn, can affect the formation of ingroup norms and specific goals (e.g., pursuing the goal of establishing precycling in the neighborhood). They proceed on both "deliberate and automatic processing levels" [24] (p. 245).

In Figure 1, we outline the relations just described and illustrate how we apply SIMPEA to our research topic. Since we are particularly interested in the influence of social identity processes on responses, we focus on how the three core components of the model (ingroup identification, collective efficacy beliefs, ingroup norms, and goals) are related to given responses.

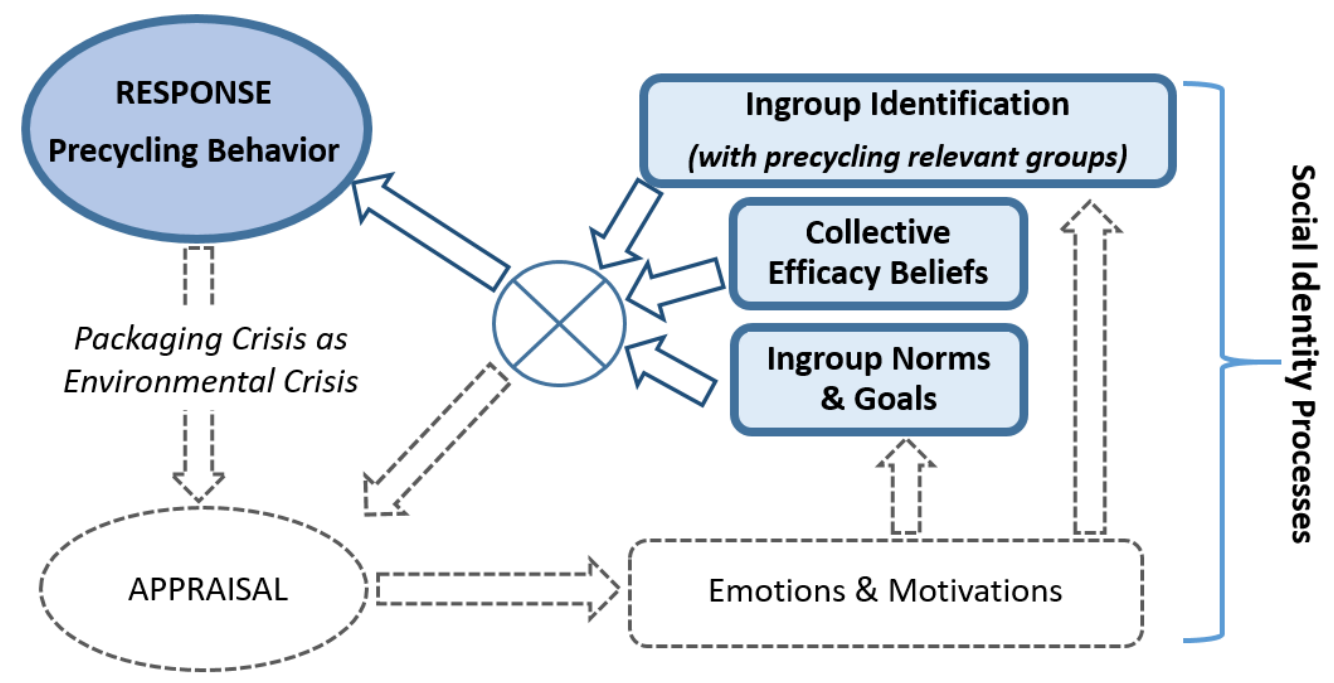

Figure 1. The Social Identity Model of Pro-Environmental Action (SIMPEA) Model applied to precycling behavior in households. The highlighted elements (in bold and blue) are the focus of our analysis. Figure adapted from Fritsche and colleagues [24] (p. 246).

Although precycling behavior has been described theoretically [23], it has not yet to our knowledge been explored empirically. What kinds of strategies do households seek to implement? What social factors and processes determine the realization of precycling? Based on the described SIMPEA model, we have formulated the following three research questions, corresponding to the model's components:

RQ 1 (Response): How is precycling behavior implemented in households?

As stated by Fritsche and colleagues, "most groups that people belong to have not been founded to fight for the environment"; nevertheless, these ordinary groups should be considered as well when it comes to environmental issues [24] (p. 251). Thus, we are interested in exploring the range of perceived ingroup identifications which are salient for households-as "ordinary" non-activist groups—and how these influence precycling behavior.

RQ 2 (Ingroup identification): What perceived ingroup identifications are salient for "ordinary" households, and how do they influence domestic precycling behavior?

Based on insights gained regarding the precycling behaviors of the studied households and their related ingroup identifications, we aim to explore related social identity and group-level processes. As outlined in Sections 1.1 and 1.2, social identity approaches propose that interactions within groups, together with salient ingroup identification, fuel social identity processes. In the presence of these processes, social, cognitive, or emotional 
resources could be released towards promoting group-based precycling behavior and cooperation within a given group. To cast light on the circumstances fostering precycling within different social groups and their salient identities, we explore the range of social identity processes influencing precycling behavior among households.

RQ 3 (Social identity processes): What social identity processes influence domestic precycling behavior?

In the following section, we describe the materials and methodology employed to answer our research questions.

\section{Materials and Methods}

\subsection{Data Collection}

All subjects gave their informed consent for inclusion before they participated in the study. The study was conducted in accordance with ethical standards. To explore precycling behaviors within households, we conducted a combined research diaries and virtual interviews study. This qualitative approach was important for three reasons: to gain a vivid and authentic impression of the role packaging plays in each household's food routines, understand their concepts of packaging prevention and explore the different facets of packaging use and disposal in their everyday lives. We collected data in April and May 2020 with citizens in Berlin, Germany. This period coincided with major restrictions upon daily life activities in terms of health protection measures taken due to the COVID-19 pandemic, including social distancing, closed schools and kindergartens, closed restaurants and cafés, reduced on-site work times or home-office. We chose this time frame for data collection, since we have assumed that people might reflect more on their everyday life and related routines during this period of rupture, namely under the pandemic-induced lockdown conditions. We considered this time for reflection as important for the study, since we wanted to analyze packaging waste and precycling as part of the normal everyday practices of private households which have usually been shaped over time into a routinized process [56].

Between the 8th and 25th of April 2020, we recruited 70 potential participants through a variety of mailing lists (Berlin district management, institutional contacts, an environmental NGO). To generate a heterogeneous and informative sample covering diverse living circumstances, we then created the final sample based on sociodemographic characteristics, place of residence within the city (postal code) and household composition (single, couple, family, flat sharing). In particular, we strove towards achieving diversity in terms of household structure so as to represent a range of household group types and characteristics. The final sample came down to 26 participants. The participants in the sample represent a cross-section of all major districts of Berlin. Each participant received compensation of EUR 50 for taking part in the study.

For a period of 7 days (4th to 11th of May 2020), participants monitored and described their daily eating routines and the resulting food packaging waste, documenting their practices in a semi-structured diary sheet that was prepared by the research team (for an example, see Section 3.1). The advantage of using this method is that information is recorded close to the time of occurrence. In this way, routinized or unconscious behaviors which are usually difficult for most people to remember and report can be captured close to their naturally occurring state; moreover, the diaries can help to stimulate memory and guide discussion during interviews [57-59]. By instructing the participants to document their routines and the resulting food packaging waste, we aimed towards making their routines and behavioral results visible so as to stimulate initial reflection upon the topic. In addition to increasing the accessibility of such information for us and facilitating participant discussion of their routines during the interviews, the diary entries informed us about whether these behaviors were performed individually or if other household group members were involved. This gave us initial impressions regarding ingroup interaction within the participants ${ }^{\prime}$ households, which were further explored during the interviews. 
After the diary-keeping period, from 14th to 28th of May 2020 we conducted semistructured virtual interviews in German with the participants, discussing what they had reported in their food diaries (see Supplement S1 for interview guide and questions). The mean length of the interviews was $60 \mathrm{~min}$, ranging from 39 to $85 \mathrm{~min}$. During the interviews, we first encouraged participants to report on their experiences freely and describe their nutrition routines before and during the COVID-19 pandemic, also taking into consideration the roles of other household group members. Then we moved on to addressing the content of their diary entries and asked them about their prevention behaviors related to food packaging (precycling). Among others, we interviewed them about their concepts of and ideas about precycling, their experience with and behavioral strategies for precycling, their motivation for becoming engaged with the topic, and perceived facilitative factors and barriers. We also asked about the perceived influence of significant others on their packaging-related behaviors. Since the term precycling is not common in Germany, we used the term prevention of packaging (in German: Verpackungsvermeidung) in the interviews.

\subsection{Characteristics of the Sample}

Of the 26 participants, 19 were female and seven were male, with an age range between 20 and 78 years (mean $=42.12$ years old). Relevant demographic data of participants are listed in Table 1. Overall, at the time of the study 19 of the participants were living with at least one other person (household-group) and seven were living alone (no group). The internal constellations of the selected household groups were diverse-including households consisting of mother and son, grandmother and grandson, young couple with child, patchwork family, sisters, couple without children, and flat-sharing groups-with group sizes of between two and four people (see Table A1 for detailed characteristics of the participants). For this study, we analyzed both participants living in household-groups as well as participants living alone. As explained above, the interviews with participants living in household groups were analyzed with special emphasis on understanding the roles other ingroup members played within the household's precycling behaviors. Additionally, responses from all interviewees concerning the views of people outside of the household regarding precycling and their influence on their own practices were considered.

Table 1. Demography: gender, age, occupation, household type.

\begin{tabular}{cccccccccccc}
\hline \multicolumn{2}{c}{ Gender } & \multicolumn{2}{c}{ Age } & \multicolumn{3}{c}{ Household Type } & \multicolumn{3}{c}{ Occupation $^{1}$} \\
\hline Male & Female & Range & Mean & Couple & Family & Shared & Single & E & S & R & U \\
7 & 19 & $20-78$ & 42.12 & 4 & 8 & 7 & 7 & 13 & 8 & 4 & 1 \\
\hline
\end{tabular}

${ }^{1}$ Occupation: $\mathrm{E}=$ Employed, $\mathrm{S}=$ Student, $\mathrm{R}=$ Retired, $\mathrm{U}=$ Unemployed.

\subsection{Data Analysis}

All 26 interviews were audio-recorded, anonymized, transcribed verbatim (see Supplement $\mathrm{S} 2$ for the rules of transcription followed) and then analyzed using ATLAS.Ti 8 [60]. The material was coded based on qualitative content analysis [61], using a coding system inspired by the above-described SIMPEA factors response, ingroup identification and self-categorization. We first coded about half of the interviews with this coding scheme and then, after reviewing the results, revised the scheme and repeated the coding procedure with all 26 interviews. The inter-rater reliability of the coding scheme was tested by a neutral person using Cohen's Kappa ( $K=0.86)$ on $20 \%$ of the data (five interviews). This test resulted in us modifying some codes. With respect to the research questions outlined in Section 1.2., our main goals during this analysis were to explore the ways in which behavioral patterns associated with packaging prevention were manifested in the studied households (response) and to identify the social ingroups (ingroup identification) shaping respondents' behaviors. The interviews of the participants living in household groups were analyzed with regard to the impacts of household group dynamics on precycling behaviors within the household. Statements regarding non-household ingroups with which 
interviewees identified and reported influencing their precycling behaviors were also considered for all interviewees. Moreover, we evaluated the data from the research diaries by counting the reported pieces of packaging waste which emerged during the 1-week diary-keeping period and analyzing whether other people were involved in the participants' activities. After identifying precycling-relevant ingroups, we deepened our analysis of particularly significant examples and explored the range of underlying processes (social identity processes) which seemed to have shaped the reported precycling behaviors.

\section{Results}

In this section, we present our empirical results. First, we outline how precycling behaviors are realized in the studied households (response, Section 3.1) and, then, report on precycling behaviors that were performed with the involvement of other group members (Section 3.2). Subsequently, we reveal the participants' self-reported descriptions of packaging avoidance and show the range of ingroups the participants mentioned that were relevant for their precycling behaviors (ingroup identification, Section 3.2.1). Further, we examine the range of related social identity processes shaping precycling behaviors within these groups and outline aspects of intra-group interaction (collective efficacy beliefs; ingroup norms and goals; Section 3.2.2).

The interview quotations have been translated from German into English by the authors.

\subsection{Realizing Domestic Precycling: A Pro-Environmental Response}

All participants were familiar with strategies to prevent food packaging and reported engaging in related behaviors, although they did not call it precycling and often did not think about it consciously as prevention of waste. When asking the interviewees about their personal ideas and practices regarding food packaging avoidance, they reported heterogeneous definitions and behaviors. According to the participants, packaging can be avoided in a number of ways, varying in their degree of complexity, difficulty, and resulting prevention potential. In accordance with the scheme devised by Klug (2018), the participants exhibited three types of precycling behavior: reduction of packaging, (total) prevention, and self-production of food products (see Table 2). For example, participants (abbreviated below as $\mathrm{P}$-or I for interviewer-prior to quotations) avoid packaging through buying loose food and bringing their own bags or boxes, which represents behavior aimed at total prevention:

P: Something like bags in the supermarket. I don't take any bags with me and, of course, lettuce doesn't have to be packaged. I don't need a [plastic] mesh fruit bag for that. I can pack it into my jute bag simply like that. That way, I avoid [packaging].

(Single household no. 6)

Beyond that, we identified three additional types of precycling undertaken by some participants: reusing of packaging, participation in group-based concepts of food acquisition, and renunciation of products instead of consumption. First, reusing of packaging represents a behavioral action to preventing the already arisen single-use packaging from becoming waste. The packaging is reused for original or different purpose. While reduction of packaging is rather taking place at the point of sale, reusing packaging is realized during or after the phase of using the respective product. Second, we added the type participation in group-based concepts of food acquisition, such as food sharing or community-based agriculture, presupposes a certain degree of (e.g., social, material, technical) infrastructure. This type will be explained more in detail in Section 3.2.3). Third, renunciation of certain packaged products represents more a general rejection of consumption. Some participants mentioned renouncing such food products which require packaging, for example take-away meals in single-use boxes, bottled water, or certain kinds of cheese that cannot be bought without packaging. In Table 2, we present the range of precycling behaviors reported by participants with reference to the characteristics proposed by Klug, including our own additions. 
Table 2. Characteristics of precycling behaviors (columns one and two), as proposed by Klug [23], combined with reported behaviors of interviewees (column three). In column three and below the dotted line, we extended Klug's characteristics with further categories and behavioral expressions of precycling (in italics). In column four, we present the number of participants who reported to realize the respective precycling behavior described in column three.

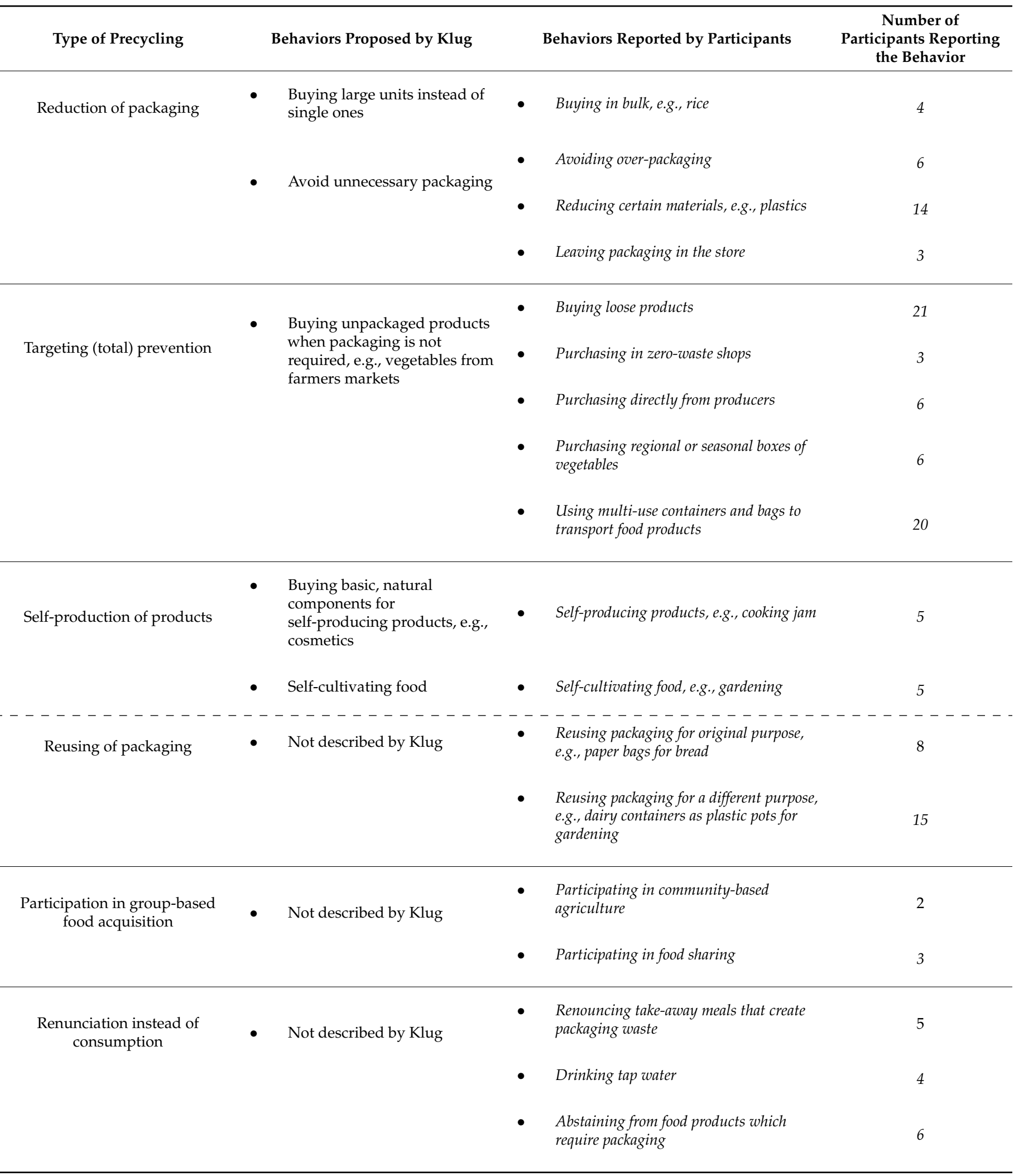


All 26 participants reported avoiding packaging in their daily nutrition routines by implementing some of the above-mentioned precycling behaviors, although the degree and extent of their adoption of these precycling behaviors varied. Some participants avoided food packaging when it remained convenient, whereas others pursued a "zero waste" goal. Consequently, as revealed through the study's diary documentation, the reported amounts and characteristics of food packaging waste generated during the week of data collection varied between households, ranging between 13 and 135 pieces of food packaging waste per week (mean = 49; for detailed volume of packaging waste, see Table A2, in Appendix A).

Most participants shared responsibility for activities related to consumption involving food packaging (e.g., planning of food purchases, purchase of food products) with other members of their household, or they realized these activities together with household members or others, such as friends, family, or neighbors (for an example of a diary entry, see Figure 2).

\begin{tabular}{|c|c|c|c|c|c|}
\hline iif & Wer han chingetour? & Wo wurde eingekautt? & $\begin{array}{l}\text { We wet was der Enbouts- } \\
\text { ort entternt? }\end{array}$ & 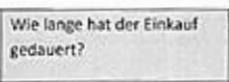 & Was wurde eingek kautt? \\
\hline $\begin{array}{l}\text { Montag } \\
\text { S. MA } 2020\end{array}$ & ich & idl & $600 \mathrm{~m}$ & $30 \mathrm{~ms}$ & 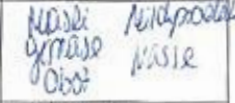 \\
\hline $\begin{array}{l}\text { Oiensteg } \\
\text { S. Ma } 2020\end{array}$ & Wf- Whataris & Aldi & $800 \mathrm{~m}$. & 2564. & 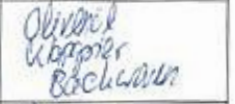 \\
\hline $\begin{array}{l}\text { Mitrwest } \\
\text { 6. Mo } 20200\end{array}$ & ich + Sroverions. & $\begin{array}{l}\text { Pelequere } \\
\text { Lidi } \\
\text { Nette }\end{array}$ & $\begin{array}{l}\text { cherowl } \\
\text { Werbizut }\end{array}$ & upenchialech & $\begin{array}{l}\text { gimole } \\
\text { Hummes } \\
\text { Toiftel }\end{array}$ \\
\hline $\begin{array}{l}\text { Donnessisg } \\
\text { 7. Mal } 2020\end{array}$ & ich & Lide & $600 \mathrm{~m}$. & $30 \mathrm{~m}$. & $\begin{array}{l}\text { Gomisestarien } \\
\text { Milupodule }\end{array}$ \\
\hline $\begin{array}{l}\text { frethes } \\
\text { 8. Ma } 2020\end{array}$ & Freunden & Spatis Guarainab] & $\begin{array}{l}\text { melharo } \\
\text { litioneiter }\end{array}$ & mind. $60 \mathrm{~m}$. & Chit teildenger \\
\hline $\begin{array}{l}\text { Samstog } \\
\text { 9. M2: } 2020\end{array}$ & 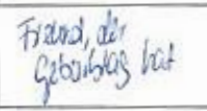 & Lal/Eda & selar nah & " & $\begin{array}{l}\text { Gillarsut } \\
\text { Plised pate }\end{array}$ \\
\hline $\begin{array}{l}\text { Sonontag } \\
\text { 10. Mai } 2020\end{array}$ & mill alten & 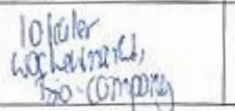 & $\begin{array}{l}1,5 \mathrm{~km} \\
500 \mathrm{~m}\end{array}$ & $1,5 \mathrm{Sid}$. & $\begin{array}{l}\text { Gmish } \\
\text { Fenlios } \\
\text { Jich }\end{array}$ \\
\hline
\end{tabular}

Figure 2. Example of a completed diary sheet, with information on the participant's purchasing behavior for the period 4-10 May 2020.

With regard to the undertaking of various precycling behaviors, the interviewees revealed that precycling is not only realized individually (by one person) but also in groups (involving at least two persons), consisting of jointly enacted behaviors within their household group or together with people from other social ingroups the interviewees identified with. In this regard some participants mentioned engaging in precycling together with members of a variety of social ingroups, namely their household group, family members, friends, colleagues, neighbors, community-based agriculture groups, or a food sharing group. A 45-year-old nursery school teacher, for example, outlined clearly how joint precycling can be realized. She and some of her colleagues bring items arising from single-use packaging from their homes to their workplace, collect these boxes and reuse them, sort and store materials for their pupils. This type of precycling corresponds the reusing of packaging. The behavior is an example of reusing for different purpose (see Table 2):

P: Some boxes and things like that we take with us to school, and some other colleagues do the same. They are then used as containers for study cards or something else. Theyboxes of margarine or something similar-are sometimes collected and decorated with stickers so that the children can use them when they work at their stations.

(Family household no. 2) 
We analyzed that joint precycling seems to presume some form of social interaction and communication between those involved (for detailed analysis of the related processes, see Section 3.2), and precycling in group contexts can result from conscious individual or collective and interactive decision processes. However, engaging in precycling does not always presuppose an intentional or active decision process but, rather, also happens unconsciously. For example, a 20-year-old male student, who lives in a shared flat, experiences both: He remembers a situation when his group of friends actively decided to choose the unpackaged product. However, he auto-explained that he experiences the avoidance of food packaging as an internalized and automatized part of purchasing food more often. Such processes and behaviors seem to be influenced by unspoken and shared ingroup knowledge and norms regarding packaging, as the following statement reveals:

P: But most of the time there is no dispute, like saying 'No, I'd rather have the wrapped potatoes.' Instead, these are things that you might not even consciously pay attention to. [...] So there have certainly been situations where we have said, "We'd prefer to take the unpackaged product". But, of course, it's often the case that you have friends who are similar and think alike. [ ... ] So it's not that one discusses it much [with friends]. So many things just seem to be common knowledge nowadays.

(Shared flat household no. 3)

Moreover, people who precycle do not always claim such behaviors to be a form of pro-environmental action nor do they explicitly identify themselves as particularly environmentally concerned or as a precycler. A 23-year-old male student stated that he does not always pay attention or strive to prevent packaging; rather, health factors regarding nutrition have priority for him. Nevertheless, he said that he does avoid buying certain products due to their excessive packaging. Meanwhile, other interviewees did explicitly see their precycling as an intentional behavioral response to counteract the global waste packaging crisis, which they considered to be an environmental and social threat. From their point of view, conscious precycling contributes towards the collective duty of preserving the earth as a habitat for current and future generations and all living beings. Participant FH2, for example, a 54-year-old nursery school teacher, purposefully precycles in mutual agreement with her son. Apart from her joint precycling in their household ingroup, she also calls attention to the packaging crisis and encourages other ingroups such as family and friends to join in precycling. Her determination and commitment to act seems to result from her awareness of the problem, combined with her identification with current and future generations.

P: Well, actually it's like this. My son, he's on the same line with me, and sometimes he tells me new things he read or heard. What we can, if possible, or can't integrate into our daily life. Apart from that, I have to say that we are the ones in our family or circle of acquaintances who bring such things to [the attention of] other people [smiling voice], because they don't care about it or something like that. And that sometimes we have already set an initial spark in some way. [ . . . ]. Sometimes I argue like this, when people react with ignorance, then I always say in some way, 'well, you don't have children'. So sometimes I see them a bit as egoists. That they live like that, they live like that only for today and don't even care about their environment. They don't recognize or don't care that this entails a slew of problems. That other generations have to deal with it somehow.

(Family household no. 2)

To address our first research question, we see that the spectrum of household precycling is broad, with a range of different behavioral strategies being implemented, either unconsciously or consciously, by all of our participants-both as a part of their daily routines and as a behavioral response to the packaging waste crisis. Moreover, precycling includes behaviors which can be realized individually as well as within group contexts, involving different ingroups and different types of social interaction. These types of behavior can be applied simultaneously by household members of various ingroups and co-exist within their collective ("we") social identity (see Figure 3). 


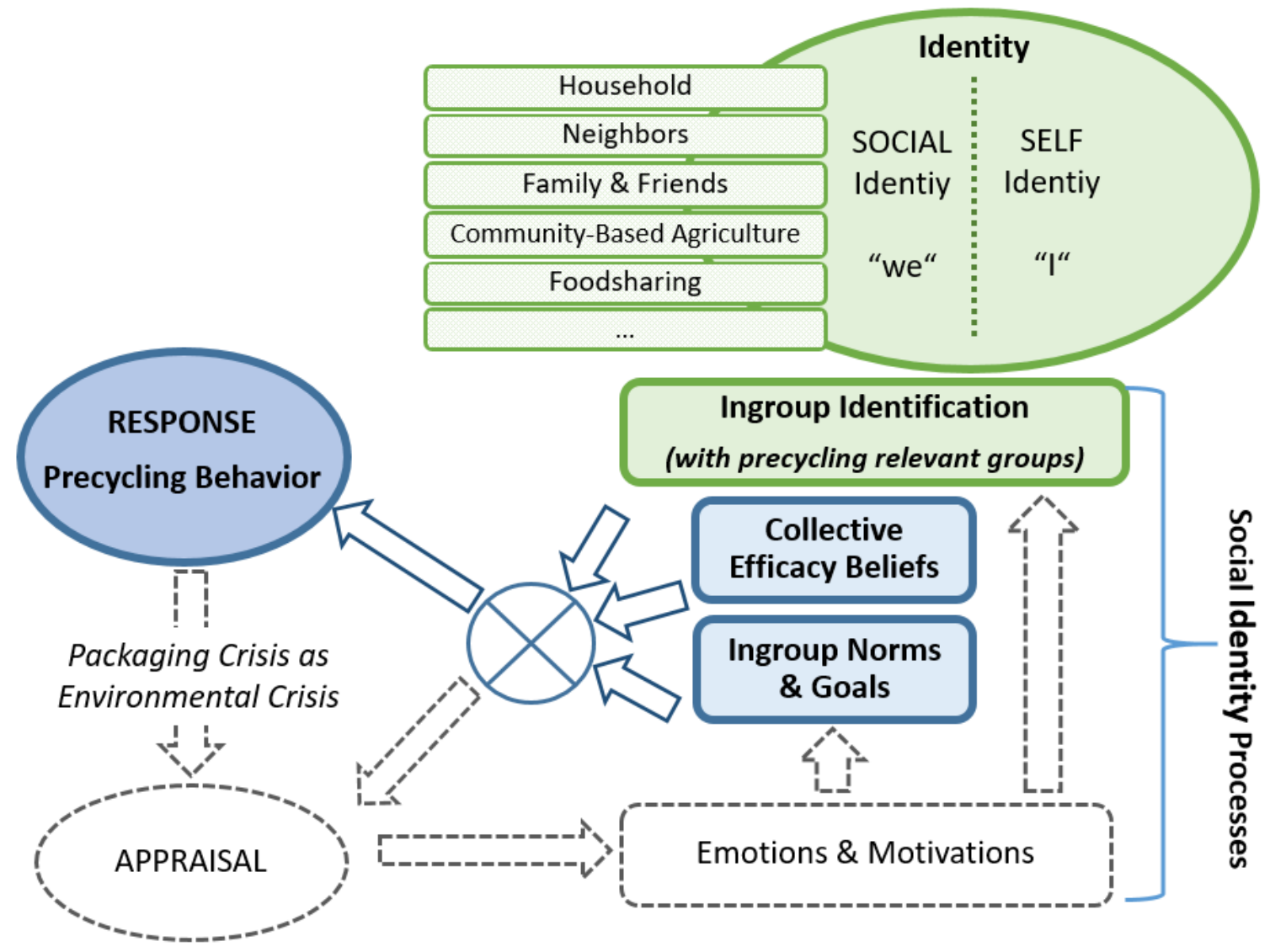

Figure 3. Forms of ingroup identification influencing precycling behaviors, as related to ingroup norms, ingroup goals, and collective efficacy beliefs. Figure adapted and extended from SIMPEA [24] (p. 246).

\subsection{Ingroup Identification and Further Social Identity Processes Influencing Domestic Precycling Behavior}

In this section, we analyze participants' self-reported descriptions of packaging avoidance and, first, examine the range of ingroup identifications the participants mentioned being relevant for their precycling behaviors. Then, we examine the precycling behaviors that were performed with the involvement of other group members and explore the range of the related social identity processes shaping precycling behaviors within these groups.

As presented in Section 3.1, some of the interviewees described how they precycle together with members of various salient ingroups with which they identify: their household group, family members, friends, colleagues, neighbors, community-based agriculture groups or food sharing groups. The statement of a 70-year-old pensioner who participates in a community-based agriculture represents a vivid example of ingroup identification in the context of precycling:

$\mathrm{P}:[\ldots]$ the average age of the members is quite low, I am one of the oldest and ehm, but

I think that I have always done quite good (... ) there and I feel well integrated.

(Single household no. 5)

To him, community-based agriculture is more than a strategy to purchase unpackaged or minimally packaged products. It also has a social meaning to him. The participant states to feel well integrated and identifies as a valuable group member. This in turn seems to influence his engagement for collective precycling, as outlined in Section 3.2.3.

The mentioned ingroups differ in size, composition, purpose, emotional proximity, and spatial proximity. Despite these differences, the groups also have several key characteristics in common: in particular, they are non-activist groups and have not been explicitly founded to fight the environmental packaging waste crisis. Instead, the initial purposes of these 
"naturally" formed groups included cohabiting, friendship or the prevention of food waste (e.g., food sharing initiatives). Nevertheless, participants do not seem to only act individually, as some perform precycling together with other group members ("we") and, thereby, could be considered to be responding collectively to the packaging waste crisis. Based on our analysis, we assume that these particular groups form part of each participants' social identity, meaning that they perceive themselves as members of these groups and derive elements of their self-concept from their knowledge of and emotional attachment to them. Knowledge about a given group includes such things as familiarity with the salient positions its members hold towards precycling (see Section 1.2). Hence, when some group members are favorable towards precycling and practice it themselves, this ingroup norm is likely to become part of the social identity of other group members and affect their behavior. The emergence of precycling behaviors in groups is determined by a number of social identity processes, as we outline in the following sections, where we explore in detail precycling behavior in three different groups that our participants identify with: household (Section 3.2.1), neighborhood (Section 3.2.2), and groups of collective food acquisition (Section 3.2.3). In Figure 3, we schematically present the examined ingroup identifications influencing precycling behaviors among our study participants, as related to their ingroup norms, ingroup goals, and collective efficacy beliefs, based on our modified SIMPEA framework (see Figure 1).

\subsubsection{Precycling in Household Groups}

Our interviews reveal that household groups represent a relevant group form for joint domestic precycling. Many participants living in household groups reported precycling together with one or more members of their household. The household group can, thus, be considered relevant for two reasons: First, by sharing space and routines, household members are likely to influence each other regarding their handling of food packaging (see Section 3.1). Second, the household group forms a key element of social identity, meaning that participants perceive themselves as members of this group and derive aspects of their self-concept from their knowledge of and emotional attachment to it (ingroup identification). This, along with shared norms and goals within the group, can have effects on their precycling behaviors. A 28-year-old student, living in a shared flat, illustrates how salient ingroup norms can influence precycling behaviors. According to the young woman, her flat mates are very concerned about packaging waste (appraisal) and avoid packaging by self-producing certain products (response). She stated that being a member of this household group (ingroup identification) and experiencing the affirmative knowledge exchange and precycling habits of her flat mates-an expression of injunctive and descriptive ingroup norms - raised her awareness regarding the topic, motivated her to conform to the group norms, and animated her to join the group's precycling activities:

P: And, because of that, somehow a completely different consciousness evolved. And when people talk about the fact that they now make their own hair gel-total luxury in my opinion -. and, when you notice that others in your family and friends are doing the same, then you are much more likely to participate than if the all of people around you don't give it any thought at all or even have a negative attitude towards it.

(Shared flat household no. 4)

The above quote implies that the salience of precycling-friendly descriptive and injunctive ingroup norms can stimulate domestic precycling behaviors in a household group as well as that, through interaction with close contacts outside one's household group, salient ingroup norms that have the power to shape behavioral response can be encountered.

Another way in which precycling behavior can be shaped is illustrated by a male participant, who described himself as being aware of the packaging waste problem but admitted not always paying attention to it. Based on his statements, we assume that his own precycling behavior depends on the salience of particular ingroups he is involved with and their respective norms. When interacting with friends whom he considers to have 
greater awareness of the problem and more frequent and advanced pro-environmental behaviors than his own, he is receptive to hearing about their shared experiences and knowledge related to precycling. Such exchanges seem to encourage him to precycle (more often) as well. On the other hand, when he interacts with friends whom he sees as having less awareness of the problem than he does, he tends to modify his behavior in the opposite direction, towards the ingroup norm, because he does not want to oppose it by negotiating the group's behaviors and arguing morally.

P: Sometimes there are just friends who somehow pay more attention to it and sometimes they say, 'Yes, I don't know, you can also get it unpackaged or something like that'. And sometimes-well, that's actually rather the case-there are people who pay less attention to it, and then you get carried away, just like that. Well, because I am not the type of person who pays attention to this. Normally, I would have, I don't know, maybe not bought a candy bar. Primarily, I think, because it is unhealthy but also because of the packaging. It's first wrapped in cardboard packaging, and then there is plastic packaging around it. And that's just not necessary. But if you meet with others and they say, 'Yes, okay, let's get something to snack on', then that's what you do. It's not like I'm going to play the moralizer and say, 'No, absolutely not'.

(Family household no. 3)

This example indicates that situations of social comparison and interaction tend to determine which norm becomes the ingroup norm and whether this ingroup norm will shape group member's behaviors. The next quotation emphasizes the importance of ingroup goals. A 45-year-old actress described how the moving experience of hearing about marine pollution from her flat mate led them to actively appraise the threat resulting from packaging waste. Consequently, they became motivated to jointly develop a shared goal and respond to the crisis by avoiding plastics:

P: He [the roommate] had seen islands of plastic [in the ocean]. And he came back, totally motivated, wanting to avoid all kinds of plastic and stuff [laughs]. And then I realized how important it is to simply see what kind of damage that causes. [ . . . W We had these plastic bags that we use for organic waste, and [I] said, no, I've already read about them, those won't break [are not degradable], and then we started buying them made of paper.

(Shared flat household no. 2)

In contrast, disagreement concerning packaging-related group goals and norms can obstruct joint precycling. A 32-year-old student lives with his grandmother and reports difficulties regarding avoidance of packaging in their daily routines. When sharing the responsibility for purchasing food, he has experienced obstacles to precycling because of conflicting goals and differing priorities between himself and his grandmother. His decisions to buy certain products are guided by his goal of avoiding food packaging, whereas his grandmother has other priorities. Based on the participant's description, however, we do not know whether he attempts to argue or negotiate with his grandmother on the packaging topic to develop a common position. Meanwhile, when he alone bears the responsibility for organizing food purchasing-or together with his like-minded girlfriendthen packaging prevention becomes easier for him. In his case, it remains ambiguous whether we are witnessing a group conflict or an interpersonal conflict regarding deviating norms and goals, as evidenced by the following exchange:

P: With my grandma, it is sometimes the case that when she is ... If she goes shopping ... and she likes something, or where she thinks she can make us happy with it, even though it might contradict my personal packaging goals a little bit, she would get it anyway, which of course results in more packaging.

I: And, in terms of packaging avoidance, when you try to do that, what do you find easy or what do you find difficult about it? 
P: (longish pause) Well, difficult maybe, is when if I know I have to get something for the household, for my grandma, because she requested something, then I also want to find the right thing that I think is acceptable to me.

(Family household no. 8)

In addition to ingroup norms and goals, collective efficacy beliefs influence participants' precycling behaviors. A male participant, 59 years old and cohabiting with his spouse, described how they jointly refuse food packaging by leaving it in the supermarket, which they consider a form of protest against the packaging waste problem. Although they assume that their two-person protest is not likely to provoke rapid systemic change, they do believe in their collective capacity to promote change. They already envision how the participation of many people in such actions of collective refusal of packaging could build up pressure on retailers and the production system to reduce food packaging (collective efficacy belief). Additionally, regarding the need for collective action, this participant calls for systemic precycling approaches to create change. As explained here, he perceives and understands the packaging problem as a complex and dynamic phenomenon which requires multi-level approaches:

P: Yes, we are constantly trying to [avoid packaging]. So, we also try to, somehow, to, I say, well, protest against it sounds so dramatic. When we remove the packaging on site and leave it directly with the retailer, it won't likely be noticed that someone is protesting (laughs) by leaving external packaging behind. But, in our minds, I then imagine: If everyone did it that way, then they would realize what kind of garbage they are accumulating. Maybe they would then put pressure on their suppliers. So that they could simply produce with less packaging. That's what was said at some point many years ago, and I try to live by that somehow. Even though I know that me-alone-I cannot change anything about it and that it can only be improved systemically by as many people as possible sticking to it.

(Couple household no. 2)

The above-presented interview transcript passages illustrate the interrelationship between appraisal; ingroup identification with the household groups; and ingroup norms, goals, and efficacy beliefs, indicating that these processes can very well influence group precycling. The following example of a 31-year-old father and teacher of environmental education suggests that the described processes also might proceed cyclically. In the first iteration of this cycle, the participant appraises the current proliferation of food packaging as posing a threat to the environment and humans. His identification with current and future generations and his motivation to ensure a good life on earth affirm his desire to act and to respond to this situation:

P: And from the perspective for my generation, but also for future generations, to make life pleasant on this planet, I honestly consider this path to be without alternative.

(Shared flat no. 5)

Consequently, he precycles together with his girlfriend and her family. This joint response, he said, is influenced by emotions and goals, as their household group feels enthusiastic about developing precycling ideas, goals, and strategies together:

P: Well, sometimes an idea originates from me, and sometimes from my girlfriend. I think we inspire each other to develop avoidance strategies as well.

(Shared flat no. 5)

The next excerpt reveals how the responses of his household group have the potential to further initiate a second cycle of appraisal and response. By precycling, the participant aims to exemplify precycling for others-to inspire and motivate them to join in. Therefore, he also introduces new precycling-friendly descriptive norms:

P: I honestly think that there is no alternative to this path. And I think that, if I can't behave this way myself, and if I can't live it in a good and simple way, it will be difficult 
to inspire other people. So, I feel bad about myself if I say one thing and do another and, on top of that, it has become a bit of a hobby.

(Shared flat no. 5)

These examples can be said to demonstrate how ingroup norms and identities partly emerge and develop through social interaction, discussion, and negotiation regarding precycling within groups, which in turn influences individual or group responses. Aside from such experiences within their household groups, some interviewees also reported that their precycling efforts have been influenced through interaction with their neighbors or by participation in group-based systems of collective food acquisition, as will be described in the following sections.

\subsubsection{Precycling in the Neighborhood}

Neighbors may regularly interact within a defined shared physical or digital space, including digital neighborhood networks. Altogether, six of our interviewees stated that neighbors influence their own precycling behaviors or, vice versa, that they influence their neighbors' behaviors-either positively or negatively. Especially for people who live alone, their neighborhood seems to act as an important social group for identification and interaction regarding precycling. A 72-year-old pensioner, for example, evaluates her relationship and interaction with her neighbor very positively and sees their informational exchanges regarding precycling ideas and strategies as being inspiring and supportive:

P: It would only be important for me if I receive good advice. Well, I have a very nice neighbor, and we exchange a lot of information, and I also listen to what he says.

(Single household no. 2)

From this example, we can see a number of social identity processes at work. First, the relationship and interaction between the neighbors are salient and positively evaluated, and the interviewee seems to self-categorize herself as a member of the neighborhood, talking about her very nice neighbor (ingroup identification). Thus, the social group consisting of her neighbors seems to form part of her social identity. Further, both neighbors here seem to agree that precycling is a relevant topic and share their experiences and plans regarding it (shared norms and goals). Moreover, the male neighbor's informational advice seems to be evaluated positively by the interviewee and, consequently, influences her precycling behaviors as she states listening to what he says (response).

In addition to the exchange of knowledge recounted above, packaging materials are also exchanged and reused collectively by the interviewee and her neighbors, representing a vivid example of cooperation and joint action:

P: And, but me, I dispose very few glass jars, because I collect them when empty and clean them. There are also some friends of mine in the neighborhood who like to preserve food and need such jars, or cans, and I give these to them after I have collected a few. [not understandable words here] It is a swap, yes. Or neighborly help. I have the feeling that they still have a use.

(Single household no. 5)

This example of the 70-year-old pensioner also illustrates the relevance of social identity processes for precycling. By exchanging material resources, these neighbors support and enable each other in reusing food packaging (response). As a result of this collective effort, the interviewee seems to feel effective (collective efficacy belief) and relieved, because through collective reuse the lifecycle of the food packaging has been prolonged before becoming waste.

Apart from joint precycling between neighbors who live in the same building or street, collective precycling can be enabled in shared public spaces, where members of the neighborhood meet to exchange information and participate in activities such as communal cooking and eating (in German, Nachbarschaftsquartier). A 35-year-old participant considers such neighborhood community areas important for jointly learning and implementing precycling routines. 
I: Mhm, mhm. Under what circumstances could you succeed in avoiding packaging? Well, you have just mentioned that appropriate framework conditions must be in place, and incentives must be provided. Are there any other circumstances that would make this easier for you?

P: [ ... I Of course, for example in terms of food culture, if many people would cook together, especially in communities, then there would be less use of packaging. Or community kitchens. [ ... ] But otherwise, for example, I would say food meetings in the neighborhood, which are socio-pedagogically instructional or something like that, where people meet for a meal. There you can really save on packaging.

(Single household no. 3)

While demonstrating the presence of social identity processes in action, these examples also indicate that a neighborhood can act as a local social network where informational influence, social support, material exchange, and shared spaces can support or enable precycling behaviors.

\subsubsection{Precycling via Group-Based Systems of Collective Food Acquisition}

In addition to spotlighting the significance of household groups and the neighborhood for precycling, the interviews revealed that group-based networks or projects of collective food acquisition might contribute towards collective precycling. However, according to the interviewees, such alternative infrastructures and systems are generally not yet used by the majority. We asked a 61 one-year-old lecturer and geriatric nurse about what kind of conditions could support her in doing precycling and, in reply, she mentioned the idea of having a social network for collective food acquisition, such as together with members of her families and other families. She does not yet take part in such a network but did report on some experiences non-household family members have had while participating in a social network where they collectively organize food acquisition and, simultaneously, precycle. In the following excerpt, we can see that this social group is organized as a network of group members with different resources and responsibilities. Through personal relations and cooperation between group members and producers, they collectively implement precycling:

P: What else emerged from the conversation with our children, which I also found exciting, was that if you had such networks where tasks are divided, then one of the participating parties only needs to take care of baked goods or something like that. And then you go shopping for the whole family and distribute it yourself. But that only works if you all live in the same city. That doesn't work with us. It just works in the village. There it is rather pronounced. But we are organized a bit differently here. First of all, [in the village] the source of supply is very clear, meaning you still know the miller, so my father simply does it through his home. And my sister [and her family], they're very compliant [regarding this concept]. They get the flour from a miller, or the miller brings it over because he supplies several people in the village. And then my father acts as the unloading depot, and my sister picks it up from there. (I: Ah yes) And that is how it is.

(Single household no. 4)

Other participants reported on their experiences with other group-based systems of collective food acquisition. According to them, being a member of and participating in community-based agriculture, delivery of vegetable boxes, or food sharing has helped them reduce packaging waste and conserve resources. By ordering vegetable boxes (in German, Gemüsekiste), for example, people receive loose vegetable and fruits without or with minimal or reused packaging:

P: And now, given that they also support these local businesses, I bought a fruit and vegetable box. Of course it has a regular price, because these fruits and vegetables are all top-quality goods, so there are no flaws. But they pack a great variety. And everything I buy from there, they put in a big box, which had been used to contain fruit. Then you have the whole mix of goods inside. And then you can just take it with you. You then just 
have to dispose of this single box. So I think that's also quite good; everything is loose in there.

(Family household no. 2)

Similarly, as with household and neighborhood groups, such group-based food acquisition projects and initiatives were not initially founded to fight the packaging waste problem, and avoidance of food packaging is generally not their primary or only goal. Instead, local, fair and sustainable food production, fair distribution and prevention of food waste comprise some of the central goals of these initiatives. Nevertheless, these projects do provide something of a systemic solution for collective packaging prevention by approaching the food- and packaging-related system on different levels. We identify the group level as one integral component, because acting as a group seems to be crucial in order to achieve shared goals, such as here establishing community-based and sustainable agriculture or preventing food waste, to name a few. Here is how a 31-year-old female web-developer explains her motivation to try out a vegetable-box service:

\section{I: Why did you choose a vegetable box?}

P: I just, I thought the idea was kind of nice. I wanted to have it. I wanted to have food that comes from somewhere around here, that is definitely organically grown [through] community-based agriculture, with the idea that you go to the farm yourself a few times a year and actively help on the farm. I thought it was really nice somehow, and I was there on Sunday. It was a great experience for me to see where the food really comes from, how much work is behind the growing of vegetables, which has increased my appreciation of the food even more. And I also found it somehow nice to know who I support in some way, that I support a way of agriculture that I consider fair.

(Single household no. 1)

As reported by a 70-year-old pensioner, community-based agriculture is more than a strategy to purchase unpackaged or minimally packed food. It also has a social meaning to him. Although most members of this community are considerably younger than this interviewee, he feels well integrated and valuable as a group member. Related to his membership in community-based agriculture, the interviewee described how he supports his neighbor in engaging with precycling by picking up and bringing her the weekly vegetable box. Without this joint effort, the neighbor could not participate due to a disability. Hence, in this case, the participant's feeling of being a contributing member of his neighborhood and the community-based agriculture group (ingroup identification) seems to stimulate his willingness to take responsibility for other group members, to support them, thereby overcoming barriers and enabling his neighbor to participate in this precycling system, as mentioned here:

P: For example, the rhythm is always Thursday in this case, except for holidays, where the delivery day is changed and that means it is important for me to take the time to pick up the box on that day. At the moment, I even pick it up for a neighbor who is also a member there, but she can't leave the house because of a disability. So, I bring the box to her directly, since it's on the way.

(Single household no. 5)

The described group-based projects or even systems represent social links between production and consumption (community-based agriculture) and between retail and consumption (food sharing). We call this link "social" because these projects/system rest upon strong community ties characterized by identification with the community (ingroup identification), active involvement and participation, shared norms and goals and joint action (response). Community-based agriculture and food sharing seems to require especially strong communities_-both real and virtual/digital. Moreover, collaboration and joint action are basic conditions for running the system. With regard to packaging prevention, participating members can overcome some of the difficulties they usually experience when trying to avoid food packaging in supermarkets (e.g., lack of transparency regarding re- 
source consumption in providing products, trying to buy organic products or those without packaging etc.). Some of these difficulties become resolved due to the systems' principles and functioning. According to the 70-year-old pensioner, transparency and waste prevention as well as sense of community, participation, involvement, and attachment to places of (agricultural) production constitute central principles of community-based agriculture. He participates in community-based agriculture because he recognizes its transparency regarding production principles and direct trade. Moreover, he appreciates being a member of this community (ingroup identification) and being involved via different media channels and actively contributing to fieldwork, as outlined here:

P: I experienced it in such a way that this community-based agriculture supply and consumption is in any case more efficient, because much less has to be thrown away, since this [production and distribution] chain is also much more transparent and comprehensible for the consumer. From the producer to the consumer. And I have already been to the countryside myself, helped out in the field. That is something you can do. [ ... I One receives photos of what is taking place in the field and videos from time to time. There are some videos already so that the customer can see, even if he is not in the field, how it is run. And that, of course, is also motivating, if one can see that they really care and they give a certain transparency, I say, yes. [ . . ] And that brings about [ . . ] that also creates trust that they do their best, and you are happy to be part of that.

(Single household no. 5)

According to a 32-year-old student, participating in food sharing facilitates packaging prevention. Instead of buying food, he regularly visits a distribution point for food sharing, where food is provided free of charge. Such food is saved collectively from being wasted. Although the saved food might be packaged, the interviewee perceives the food sharing system as a way to prevent packaging, because the food, including the packaging, had already been considered to be waste. Hence, through food sharing, he conserves resources by preventing food and packaging from being wasted unused:

P: When is it particularly easy to avoid packaging? Whenever I can visit a distributor as often as possible. (Distributor = place to pick up saved food)

I: Okay. And at the distributor, the items are packed less often than in the supermarket?

P: Well, let's say broccoli is packed the same way as in the supermarket. But then I would have, well, it's wrapped in plastic wrap, but then I wouldn't have any problem taking five pieces with me. Because it was already sorted out as garbage anyway. And I don't have to pay any money for buying the packaging, the garbage, with it, because it has already been declared to be garbage [by the supermarket] prior to reaching the distributor.

(Family household no. 8)

To sum up, we have identified community-based agriculture and food sharing as group-based initiatives and systemic solutions which can contribute towards precycling. Similarly, to precycling within household groups or neighborhoods, the contribution of these group-based projects to precycling seems to be influenced by social identity processes, meaning here ingroup identification with and self-categorization as belonging to the respective group and supporting its shared ingroup norms and goals. These processes, as reported by our interviewees, became visible through their descriptions of social interactions and experiences within such groups, where interaction and communication via both digital media and live participation in relevant activities occurs.

\section{Discussion}

With our qualitative study we have thus far explored and refined the concept of precycling behavior through interviewing members of "ordinary" households. Further, we have applied the theory-based Social Identity Model of Pro-Environmental Action (SIMPEA) to a real and urgent socio-ecological problem, in order to empirically substantiate the model. In this section, we first discuss the relevance of our findings for understanding 
domestic precycling behavior (Section 4.1). Second, we elaborate their implications for theory development (Section 4.2) and, third, for intervention designs and programs on waste prevention (Section 4.3). Fourth, we address the limitations of this study (Section 4.4).

\subsection{Understanding Domestic Precycling Behavior}

Our results show that people enact a range of different strategies at home to prevent or reduce the use of food packaging, either consciously or unconsciously. Similar to previous findings regarding waste prevention [17,34], the specific ways in which precycling is carried out is diverse, as illustrated by our interviewees' conceptions and practices of packaging prevention. Precycling is not a set and consistent practice in itself and can include complex and interrelated behaviors, a finding that is in line with studies on household waste prevention (e.g., $[15,62])$.

Based on this general finding, we have been able to extend the typology of precycling behaviors formulated by Klug [23], who distinguishes between reduction of packaging, (total) prevention and self-production of products. Beyond that, we have identified three additional types of precycling implemented by our study participants: reusing of packaging, participation in group-based concepts of food acquisition and fundamental rejection of consuming certain products that entail packaging waste. This rejection of consumption seems to meet the conditions of sufficiency, in terms of "enoughness", as a sustainability strategy [35].

Although precycling stands out as a potentially prevalent form of daily practice which is implementable for many people, not every precycling strategy suits every household constellation equally well. For example, purchasing products in zero-waste stores is only feasible if such stores are located within a person's mobility radius. Future studies could examine whether and how implementation of precycling strategies varies between different types of households (who uses which strategies?) and if systematic differences regarding respective group-level processes can be detected.

Overall, our study shows that precycling, although not explicitly named as such, is a common topic among regular consumers, at least in Berlin, and not exclusively an expression of a specific lifestyle coupled with a clear precycler identity, as suggested by Klug [23]. Importantly, we have revealed that precycling is far more than an individual process and practice but is, rather, intertwined with social elements on different levels. Resonating with the ideas of SIMPEA, we suggest that precycling represents a pro-environmental response that is shaped by social identity processes and interpersonal interaction. The social identity factors of ingroup identification, ingroup norms and goals and collective efficacy beliefs can influence whether people are likely to adopt an environmentally friendly response such as precycling.

Whereas previous research on pro-environmental behavior based on social identity approaches has largely investigated groups consciously geared towards pro-environmental goals ([63-65], for a review see [66]), we have instead considered groups with different objectives-not founded for pro-environmental reasons-provided that they are associated with precycling. In this vein, our study illustrates the broad range of social identities associated with precycling behaviors (see Figure 3), providing insights regarding how such identities can influence precycling as a response to the waste crisis. As we found out, precycling regularly takes place in group contexts involving diverse social constellations, including couples, families, friends, colleagues, or neighbors, such as one interviewee reusing old packaging together with her neighbors. The participants described themselves as identifying with a range of different ingroups and engaging in precycling with them or not, depending on the prevailing norms within each group (see Section 3.2). A key common feature of these groups is that precycling was not their initial group purpose and, thus, their precycling activities do not represent a conscious striving towards activist-environmentalist goals but, rather, form part of their daily life interactions within or between social groups. Thus, our study suggests that social identity processes, which were previously investigated 
largely in political activist and environmentalist groups [24] (p. 249) [67,68], similarly exist in small, natural groups such as households or neighborhoods.

Interaction with group members and identification with ingroups influences domestic precycling behavior and can both support or complicate it. While shared ingroup norms and goals can contribute towards embracing precycling behaviors, conflicting norms and goals within or between groups can complicate or hinder precycling behaviors. For example, the precycling habits of a 23-year-old male participant (Family household no. 3) depended on the salience of his particular friend groups and their respective ingroup norms (see Section 3.2.1). In friend groups with greater awareness of the packaging waste problem and higher levels of pro-environmental behavior, he was more open to the topic and felt encouraged to join in precycling. In contrast, when interacting within friend groups with lower awareness and minimal if any precycling habits, he conformed his behaviors in that direction and went along with the ingroup norms. Meanwhile, our study has also shown how-while precycling jointly within their self-relevant ingroups and following shared ingroup norms, goals, and collective efficacy beliefs-some participants see themselves as trying to bring their precycling activities to the next level. The example of the couple who refuse packaging by leaving it in the supermarket - to call the attention of owners and customers to the unnecessary waste and promote precycling-friendly norms-illustrates how an ordinary household group can strive to become "a true activist group" [24] (p. 251) for precycling.

In addition to relatively small and private social groups like households, friends or neighbors, we have identified community-based agriculture and food sharing as initiatives which can contribute towards greater precycling and, similarly, are based on strong social groups whose members are influenced by social factors. Moreover, within this kind of social system, the principles of solidarity, collaboration, and joint actions seem to be important in two ways: they seem to be prerequisites for running the system and represent a means of social attraction and encouragement to participate, as they fulfil some basic social needs of members. Further, through the support of such group-based systems, members can collectively overcome some of the difficulties they usually experience individually, for example when trying to avoid food packaging in the supermarket. Similar to the argumentation of a study on packaging-free shopping [36] we outlined, that group-based systems such as community-based agriculture represent an alternative (or "reinvention") [36] (p.264), to conventional systems of food acquisition (e.g., supermarket). As we have shown, these alternative means of food provision contribute towards packaging prevention among households and partly operate through social mechanisms. To participate in such alternative groups, participants had to re-skill (e.g., help with harvesting on the farm) and adjust their normal routines (e.g., adapt their time schedule to the times set for vegetable box pick-up). Furthermore, this form of collective food acquisition was meaningful to participants in new ways, as the meaning of their purchasing behavior is not only linked to the food products themselves (such as selecting a product in the supermarket) but can also be intertwined with group activities (e.g., deciding together on the pick-up time schedule or delivering a vegetable box to a disabled member). Based on these insights, we propose that social identity and group-level approaches could contribute towards reinventing food acquisition and also stimulate processes of re-skilling and re-framing. Moreover, such group-based practices can serve as inspiration for rethinking patterns of production and consumption and envisioning pathways more in accord with social and ecological sustainability.

Furthermore, our results indicate that everyday implementation of precycling within households will not necessarily prevent daily accumulation of great amounts of food packaging. The quantity and quality of waste generated by households does not represent a satisfactory criterion for generally evaluating the packaging consumption of an entire society. On one hand, packaging waste also emerges outside of households, as the production, logistics, and retail sectors generate significant amounts of packaging waste [13]. On the other hand, other aspects of resource consumption require consideration as well. 
Some participants perceived glass as an environmentally friendly alternative and substitute for plastic packaging. However, this general assumption is misleading. The levels of resource consumption and environmental effects of different materials and packaging systems depend on a variety of factors: among other considerations, length of transport routes and the potential reusability of products greatly affect environmental performance ([69], for an example of beverage packaging). We call for empirical research and public programs that take into account the complexity and interrelatedness of these factors so as to derive holistic approaches for precycling. Of course, studies on individuals and groups should also form part of such approaches.

\subsection{Implications for Theoretical Development}

Our results appear to support the general ideas of the SIMPEA framework. Nevertheless, it remains unclear how the processes and factors discussed here interact with each other before resulting in a pro-environmental response, such as precycling. Here we could ask, for example, if and to what degree low scores on one factor could be compensated by other factors. We were also not able to clarify whether the degree of ingroup identification with a precycling-friendly group significantly influences precycling behavior in the end. Future research is needed to test the model quantitatively and examine the causality of these relationships.

Moreover, besides the role of ingroup identification (e.g., being neighbors) for precycling behavior, we note that a sense of belonging and emotional attachment to a place (e.g., neighborhood) can potentially affect collective processes [70]. For example, the rediscovering or revival of neighborhood locations (e.g., weekly markets) could provide new options for precycling and establishing corresponding group norms. Thus, extending SIMPEA with the factor place attachment could contribute towards increasing the explanatory power of the model [70] for studying precycling and possibly other environmentally oriented activities. Moreover, empirical research should more carefully examine the special role of emotions and motivations. For example, although SIMPEA assumes that emotions and motivations fuel the other involved social identity processes and, thereby, indirectly influence responses, the functioning of this proposed mediation could not be tested be means of our interview data. Experimental studies could cast light on such relationships. Further, based on their statements, it was difficult to distinguish whether interviewees experienced collective efficacy (as proposed by SIMPEA) or, rather, participatory efficacy, which means the belief that the actions of an individual actor will make a considerable difference towards collective efforts in attaining a group's goal [71]. The authors of a recent study on different dimensions of efficacy beliefs, Hamann and Reese, have revealed some contradictory results and call for ongoing research on this topic [55]. Thus, we suggest that, if participatory efficacy beliefs were to emerge as equal to or even more important than collective efficacy beliefs within the context of pro-environmental action, this factor should be taken into consideration when using the SIMPEA framework.

In the present study, we have derived social identity processes from interactive group contexts, where we identified communication and interaction between group members as being decisive for the precycling behaviors of the group. However, to obtain greater understanding of precycling and related social factors and processes, small-groups dynamics, and the interrelationships between group-level and interpersonal processes need to be examined simultaneously. Some research rooted in social identity tradition provides some insights into the interplay of social identity processes and dynamics in groups [50,51], exploring actual interactions and other group-level concepts (e.g., negotiation of goals, interdependence of individual and group-level factors). This remains an important avenue for future research $[39,51]$. With regard to precycling, the relationships between interpersonal interaction in small groups and the emergence and development of social identity processes (e.g., the differentiation between conflicting group goals vs. conflicting personal goals) especially require further evaluation. Likewise, it would be interesting to investigate whether groups can generally implement precycling better or worse than individuals and 
what kinds of individual and group processes affect group performance vis-à-vis certain precycling tasks or goals.

\subsection{Implications for Intervention Design and Programs on Waste Prevention}

In this study, we have proposed that the power of "we" has the potential to stimulate precycling behaviors in non-activist groups. This argument is in accord with a metaanalysis suggesting that climate-friendly behaviors were also increased among people who identified with groups that had not been characterized as pro-environmental [72]. Similarly, to the authors of the meta study, we argue that fostering psychological persongroup bonds might be a fruitful strategy for increasing waste prevention behavior as a form of prosocial behavior undertaken by a broad spectrum of groups-beyond explicitly environmentalist groups. We propose that achieving a better understanding of social identity processes - operating both in small and private groups and in larger collectives-is promising for realizing precycling on a greater society-wide scale. Moreover, identities "are not behavior-specific" [72] (p. 12); hence, when interventions build on identities which are related to pro-environmental behavior, and when these identities remain salient in different contexts, the effects of an intervention could potentially spillover to other contexts and foster pro-environmental behaviors therein $[24,65,72,73]$. When developing interventions to foster precycling, the social identity approach represents a promising means for moving forward. Previous studies proposed strategies based on the social identity approach to considering for future interventions to foster pro environmental behavior see [24,49]. Based on these suggestions, we now concretize their proposals for precycling:

\section{Make precycling-related social identities salient}

Research on social identity processes has proposed to make pro-environmentally related social identities more salient to fostering respective pro-environmental behaviors $[24,49]$. As outlined in our results section, households and neighborhoods represent two examples of ingroup identities related to precycling. Hence, interventions should address those social identities which are relevant for precycling and salient during interaction with food packaging (e.g., during food purchasing, preparation and consumption of meals, and reuse or disposal). This implies that interventions should also address existing collectives, such as (digital) neighborhood groups, or settings where groups regularly meet and interact (e.g., the workplace, public associations, community cafés, sports clubs, or schools) and where person-group bonds are developed and fostered.

\section{Use ingroup sources as providers of information on precycling}

Interventions should involve ingroup members to disseminate messages and information regarding precycling (e.g., to household members, neighbors) because they are perceived as being more credible than unfamiliar outside sources [74].

\section{Frame precycling actions as collective project}

Precycling actions should be created and communicated as distinct and shared collective projects (e.g., establishing a neighborhood project for joint precycling) see [24] (p. 260).

\section{Develop and foster collective precycling-friendly norms}

Small-group activities are important for developing a sense of shared identity that emphasizes environmentally friendly ingroup norms and supports group members in building a broader sense of environmental identity [49]. Based and the overview and the suggestions by Fielding and Hornsey [49] (p. 7), as well as by Fritsche and colleagues [24] (p. 260), we now outline the importance of developing and fostering collective precyclingfriendly norms. Therefore,

- messages and information should be communicated by group members;

- interventions should encourage group activities which create space for interaction and discussion between group members in developing shared precycling-friendly norms and goals; 
- $\quad$ existing precycling-friendly norms and identities should be strengthened by providing messages spotlighting pro-environmental norms that are likely to bolster group members' pro-environmental attitudes and behaviors [49,75];

- negative descriptive norms which are dominant in the ingroup (e.g., great amount of packaging waste in the household or courtyard, packaging waste-intensive routines) can be attenuated through strategies such as emphasizing precycling-friendly injunctive ingroup norms (e.g., group members approve of preventing packaging waste), increasing the salience of a "superordinate identity" [49] (p. 7) that does have precycling-friendly descriptive norms (e.g., a local identity, such as when municipal initiatives promote becoming a zero-waste city) or providing "comparisons that make the ingroup appear more pro-environmental" [49] (p. 7) [76,77].

\section{Take account of developments due to COVID-19}

In view of recent developments during the COVID-19 pandemic, some previously prevalent social identities may fade or disappear, because social-distancing measures of led to levels of social interaction decreasing in some contexts (e.g., friends, workplaces, sports, culture). For example, participants of this study barely mentioned colleagues or the workplace as relevant ingroups for precycling behavior. This result can be traced back to the context conditions of the study, since many people were mainly working from home due to the coronavirus pandemic. However, colleagues and organizational culture can strongly influence private consumption behavior (e.g., [78]). In contrast, other ingroups seem to have become more important for interaction, social identification and a sense of belonging (e.g., household, neighborhood). These recent changes should be considered when developing communication strategies and interventions which operate through social identity processes [70].

In addition to social identity processes, interventions should consider the literature on intragroup dynamics regarding group-level factors, such as types of interaction, degrees of interdependence between group members, and generation and negotiation of group goals and norms [52]. These factors potentially affect resource consumption and conservation in households, as the dynamics between group members influence individual members so as to "determine an outcome that is rather a property of the group as a whole" [39] (p. 3). Insights from both perspectives could be fruitfully integrated to inspire interventions employing group-level approaches that address small-group dynamics together with social identity processes, potentially resulting in interventions that are more effective than previous ones based on individually focused concepts.

Thus far, as noted by Abrahamsen and colleagues, many intervention studies on resource conservation have not evaluated the underlying conditions and processes which determine the effectiveness of the approaches applied. Moreover, follow-up measures related to desired behavior changes subsequent to an intervention are seldom assessed but are needed to study the long-term durability of effects [44] (p. 1783). Therefore, future field studies should examine why and how interventions based on the social identity approach work and need to consider appropriate follow-up measures for implementation after completion of the intervention.

\subsection{Limitations}

Our sample consisted of a heterogeneous range of participants differing in age, gender, housing situation, financial capacities and professional background. However, the sample exclusively comprised people living in Berlin and were mostly female and well educated (17 have an academic degree). This bias might be related to our recruiting strategy, as the sample was based on self-selection by the participants. Furthermore, all participants were living in a metropolis, which reflects a particular reality in terms of everyday life. Social relations, such as in neighborhoods or associations, are likely to differ greatly in some respects between major cities, small cities, and rural areas. Another notable limitation is that, in Germany, concerns towards packaging waste are relatively present $[7,8]$ and are discussed in public discourse and daily practices; nevertheless, waste from packaging 
is constantly increasing [13]. Similar studies in other countries may reveal interesting differences or similarities regarding how environmentally friendly practices such as precycling are discussed and implemented. Further, our insights are based on self-documented and self-reported experiences and behaviors. However, we did capture some behavioral residuals through the diaries on packaging behavior and waste which have enabled us to draw some conclusions regarding the participants' actual packaging routines. Based on these residuals, we were able to validate respondents' statements to a certain degree. Nevertheless, we were not able to evaluate whether people who claim to precycle actually produce less packaging waste or if social identity processes really do influence this relationship; these are issues that need to be examined through quantitative methods.

In our interviews, social identity factors were indirectly described within complex situations and contexts; based on this, we theorized the relationships and interactions between the separate factors. We have been able to describe the roles of and relationships between the SIMPEA factors for precycling in different social groups, but the method does not allow us to make any credible claims regarding causality. Nevertheless, we believe that this qualitative approach was important, because the information we obtained would have hardly been accessible via a questionnaire. Rather, the interview situation allowed us to enter into a natural exchange on the participant's everyday experiences with packaging and their associated social experiences. This was particularly necessary for identifying the various social ingroups which seems to be relevant to the participants' ${ }^{\prime}$ precycling behaviors. In this study, we have concentrated on examining the role of social identities in the context of precycling, but we have not considered social identities related to other pro-environmental behaviors nor other kinds of identity. However, a range of identities might be relevant in the context of precycling (e.g., place identities); following the review from Udall and colleagues [66] future research may be able to clarify such relationships between different identity types and types of pro-environmental behavior.

Another limitation here is that we only interviewed one person per household-who described their own experiences and precycling behaviors but also reported on behalf of the other household members. The diaries, in contrast, were partly filled-in together with other members of the household and, thereby, allowed group members to enter into exchanges on their routines. Nonetheless, the question remains of whether all relevant characteristics of a household group can be comprehensively portrayed through the account of only one household member. However, research on this question by Seebauer and colleagues has revealed that "consistency (agreement between self-reports of household members) is higher if behaviors are undertaken jointly or negotiated between partners" [79] (p. 603), and that "accuracy (agreement of proxy-reports with corresponding self-reports) is higher for routine behaviors and for behaviors easily observable by the partner" [79] (p. 603). Our investigation has revealed that some precycling behaviors were undertaken jointly, negotiated between group members, and were also made visible through self-observation related to the diary. Hence, we assume that our respondents were able to represent the ideas and practices of their household group adequately enough. Nevertheless, future studies should consider including all relevant group members so as to gain access to as much valid and reliable information on key social identity factors and group characteristics as possible $[39,79]$.

\section{Conclusions}

We conclude that the power of "we" has the potential to stimulate precycling behaviors in a range of natural groups, including households, neighbors, friends, colleagues, and the like. In such contexts, social identity processes merit further attention and consideration, because the respective groups reflect the daily realities of many people who are not openly environmentally committed and represent a promising starting point for encouraging pro-environmental behavior. Overall, we suggest that the SIMPEA model may be a suitable framework for structuring and analyzing social identity processes within and among different social groups and in a variety of applied settings, such as precycling in households. 
The qualitative approach we have adopted has enriched our understanding of the interplay between separate social identity factors and extended the mostly quantitative research that has already been conducted in this area (for an overview, see [24]).

On the whole, we propose fostering social approaches and social innovations for creating feasible solutions to the packaging waste problem. However, total prevention of food packaging waste hardly appears achievable via consumer-oriented approaches, because consumption is highly intertwined and interdependent with production, distribution, purchase, and disposal systems. Hence, apart from consumer-centered studies, we call for systemic changes at all levels related to packaging waste and its corresponding resource consumption [6]. Such approaches should involve all relevant sectors and actors, such as transportation packaging in the logistics sector. Moreover, systemic solutions should support coordinated action between the political and economic spheres and create societal settings which favor precycling. Future precycling solutions could include innovative production and shopping concepts as well as transformation of the food supply system, among many other possibilities.

Supplementary Materials: The following are available online at https:/ /www.mdpi.com/2071-105 0/13/3/1321/s1, Document S1: interview guide and, Document S2: Transcription rules.

Author Contributions: Conceptualization, K.W.; methodology, K.W. and E.S.; formal analysis, K.W.; investigation, K.W. and E.S.; data curation, K.W.; writing—original draft preparation, K.W.; writingreview and editing, K.W. and E.S.; visualization, K.W.; supervision, E.S.; project administration, E.S.; funding acquisition, E.S. Both authors have read and agreed to the published version of the manuscript.

Funding: This research was funded by the German Federal Ministry of Education and Research under the Research for Sustainability program, grant number 01UU1901A.

Data Availability Statement: The data are not publicly available due to privacy issues.

Acknowledgments: The authors are grateful for financial support from the German Federal Ministry of Education and Research. The study is part of the junior research group "Precycling as a means of resource efficiency-Systemic solutions for packaging prevention" at the Technische Universität Berlin. Further, we would like to thank the participants who supported this research project by keeping diaries and allowing themselves to be interviewed. We thank Gerhard Reese for his comments on the manuscript as well as Anne Müller, Cassiopea Staudacher, and Rabea Dehning for their help during the data collection and preparation of the transcriptions.

Conflicts of Interest: The authors declare no conflict of interest. The funders had no role in the design of the study; in the collection, analysis, or interpretation of data; in the writing of the manuscript or in the decision to publish the results.

\section{Appendix A}

Table A1. Title of interview, household type and size, building type, district, and demography.

\begin{tabular}{|c|c|c|c|c|c|c|}
\hline Interview Title & Household Size & Building Type & District $^{1}$ & Gender & Age & Current Occupation \\
\hline Couple household 1 & 2 & Block of houses & 3 & $\mathrm{~F}$ & 28 & Student \\
\hline Couple household 2 & 2 & $\begin{array}{l}\text { Multiple } \\
\text { dwelling }\end{array}$ & 12 & M & 59 & Customer consultant \\
\hline Couple household 3 & 2 & Block of houses & 9 & $\mathrm{~F}$ & 30 & Support-employee, Editor \\
\hline Couple household 4 & 2 & Block of houses & 2 & $\mathrm{~F}$ & 28 & Scientific advisor \\
\hline Family household 1 & 2 & Detached house & 6 & $\mathrm{~F}$ & 78 & Pensioner \\
\hline Family household 2 & 2 & $\begin{array}{l}\text { Multiple } \\
\text { dwelling }\end{array}$ & 1 & $\mathrm{~F}$ & 54 & Nursery school teacher \\
\hline Family household 3 & 2 & Detached house & 10 & M & 23 & Student \\
\hline Family household 4 & 3 & $\begin{array}{l}\text { Multiple } \\
\text { dwelling }\end{array}$ & 11 & $\mathrm{~F}$ & 28 & Information scientist \\
\hline Family household 5 & 4 & $\begin{array}{l}\text { Multiple } \\
\text { dwelling }\end{array}$ & 6 & $\mathrm{~F}$ & 33 & Unemployed \\
\hline
\end{tabular}


Table A1. Cont.

\begin{tabular}{|c|c|c|c|c|c|c|}
\hline Interview Title & Household Size & Building Type & District $^{1}$ & Gender & Age & Current Occupation \\
\hline Family household 6 & 4 & $\begin{array}{l}\text { Multiple } \\
\text { dwelling }\end{array}$ & 1 & $\mathrm{~F}$ & 55 & Pedagogical assistant \\
\hline Family household 7 & 2 & $\begin{array}{l}\text { Multiple } \\
\text { dwelling }\end{array}$ & 4 & $\mathrm{~F}$ & 42 & Quality controller \\
\hline Family household 8 & 2 & $\begin{array}{l}\text { Multiple } \\
\text { dwelling }\end{array}$ & 9 & M & 32 & Student \\
\hline Shared-flat 1 & 2 & $\begin{array}{l}\text { Multiple } \\
\text { dwelling }\end{array}$ & 7 & $\mathrm{~F}$ & 26 & Student \\
\hline Shared-flat 2 & 2 & Block of houses & 8 & F & 45 & Actor \\
\hline Shared-flat 3 & 2 & $\begin{array}{l}\text { Multiple } \\
\text { dwelling }\end{array}$ & 11 & M & 20 & Student \\
\hline Shared-flat 4 & 4 & Block of houses & 3 & $\mathrm{~F}$ & 28 & Student \\
\hline Shared-flat 5 & 3 & Block of houses & 4 & M & 31 & Teamleader \\
\hline Shared-flat 6 & 2 & Block of houses & 8 & $\mathrm{~F}$ & 63 & Coach, guide, cantor \\
\hline Shared-flat 7 & 3 & tower block & 8 & $\mathrm{~F}$ & 23 & Student, part-time job \\
\hline Single household 1 & 1 & $\begin{array}{l}\text { Multiple } \\
\text { dwelling }\end{array}$ & 2 & $\mathrm{~F}$ & 31 & Web Developer \\
\hline Single household 2 & 1 & tower block & 2 & $\mathrm{~F}$ & 72 & Pensioner \\
\hline Single household 3 & 1 & tower block & 11 & M & 35 & Communication scientist \\
\hline Single household 4 & 1 & $\begin{array}{l}\text { Multiple } \\
\text { dwelling }\end{array}$ & 10 & $\mathrm{~F}$ & 61 & Geriatric nurse \\
\hline Single household 5 & 1 & $\begin{array}{l}\text { Multiple } \\
\text { dwelling }\end{array}$ & 8 & M & 70 & Pensioner \\
\hline Single household 6 & 1 & Detached house & 12 & $\mathrm{~F}$ & 23 & Student, Cashier \\
\hline Single household 7 & 1 & No information & 10 & $\mathrm{~F}$ & 77 & Pensioner \\
\hline
\end{tabular}

${ }^{1} 1$ = Mitte, 2 = Friedrichshein-Kreuzberg, 3 = Pankow, 4 = Charlottenburg-Wilmersdorf, 6 = Steglitz-Zehlendorf, 7 = Tempelhof-Schöneberg, $8=$ Neukölln, 9 = Treptow-Köpenick, 10 = Marzahn-Hellersdorf, 11 = Lichtenberg, $12=$ Reinickendorf.

Table A2. Packaging volume per household in number of units and by material type according to participants diaries.

\begin{tabular}{|c|c|c|c|c|c|c|}
\hline Interview Title & Plastic & Metal & Paper and Cardboard & Glass & Other & Sum \\
\hline Couple household 1 & 20 & 1 & 14 & 1 & 0 & 36 \\
\hline Couple household 2 & 70 & 26 & 25 & 3 & 5 & 129 \\
\hline Couple household 3 & 23 & 7 & 18 & 1 & 0 & 49 \\
\hline Couple household 4 & 38 & 5 & 15 & 0 & 0 & 58 \\
\hline Family household 1 & 44 & 27 & 11 & 9 & 1 & 92 \\
\hline Family household 2 & 61 & 11 & 30 & 3 & 0 & 105 \\
\hline Family household 3 & 12 & 1 & 3 & 1 & 0 & 17 \\
\hline Family household 4 & 22 & 2 & 5 & 1 & 0 & 30 \\
\hline Family household 5 & 55 & 2 & 11 & 0 & 0 & 68 \\
\hline Family household 6 & 37 & 10 & 17 & 12 & 8 & 84 \\
\hline Family household 7 & 16 & 0 & 6 & 1 & 0 & 23 \\
\hline Family household 8 & 15 & 0 & 9 & 2 & 0 & 26 \\
\hline Shared flat 1 & 10 & 1 & 2 & 0 & 0 & 13 \\
\hline Shared flat 2 & 6.5 & 0 & 5.5 & 1 & 0 & 13 \\
\hline Shared flat 3 & 18 & 3 & 10 & 15 & 0 & 46 \\
\hline Shared flat 4 & 18 & 5 & 15 & 6 & 0 & 44 \\
\hline Shared flat 5 & 9 & 1 & 6 & 1 & 0 & 17 \\
\hline Shared flat 6 & 9 & 1 & 6 & 1 & 4 & 21 \\
\hline Shared flat 7 & 24 & 4 & 8 & 1 & 0 & 37 \\
\hline Single household 1 & 16 & 0 & 11 & 1 & 0 & 28 \\
\hline Single household 2 & 9 & 1 & 4 & 3 & 0 & 17 \\
\hline Single household 3 & 20 & 0 & 15 & 3 & 0 & 38 \\
\hline Single household 4 & 41 & 45 & 42 & 7 & 0 & 135 \\
\hline Single household 5 & 16 & 1 & 6 & 0 & 0 & 23 \\
\hline Single household 6 & 23 & 9 & 9 & 3 & 2 & 46 \\
\hline Single household 7 & 40 & 10 & 18 & 4 & 11 & 83 \\
\hline Percentage & $53 \%$ & $14 \%$ & $25 \%$ & $6 \%$ & $2 \%$ & $100 \%$ \\
\hline Sum & 673 & 173 & 321.5 & 80 & 31 & 1278 \\
\hline
\end{tabular}




\section{References}

1. Galloway, T.S.; Lewis, C.N. Marine microplastics spell big problems for future generations. Proc. Natl. Acad. Sci. USA 2016, 113, 2331-2333. [CrossRef] [PubMed]

2. Li, W.C.; Tse, H.F.; Fok, L. Plastic waste in the marine environment: A review of sources, occurrence and effects. Sci. Total Environ. 2016, 566-567, 333-349. [CrossRef] [PubMed]

3. Royer, S.-J.; Ferrón, S.; Wilson, S.T.; Karl, D.M. Production of methane and ethylene from plastic in the environment. PLoS ONE 2018, 13, e0200574. [CrossRef] [PubMed]

4. Wilson, D.C.; United Nations Environment Programme; International Solid Waste Association. Global Waste Management Outlook; UNEP: Vienna, Austria, 2015.

5. European Environment Agency. COVID-19 and Europe's Environment: Impacts of a Global Pandemic; European Environment Agency: København, Denmark, 2020.

6. Süßbauer, E.; Wilts, H.; Otto, S.J.; Schinkel, J.; Wenzel, K.; Caspers, J.; Dehning, R.-L.; Jürgens, S. Ausweg aus dem Einweg? Auswirkungen der Coronakrise auf das Verpackungsabfallaufkommen in Deutschland. Müll Abfall 2020, 10, 498-503. [CrossRef]

7. VZBV. Verbraucherbefragung Einweg-Plastik Und Verpackung II; Verbraucherzentrale Bundesverband (VZBV): Berlin, Germany, 2018.

8. VZBV. Verpackungsabfälle; Verbraucherzentrale Bundesverband (VZBV): Berlin, Germany, 2017.

9. European Parliament. Directive on the reduction of the impact of certain plastic products on the environment. OJEU 2019, L155, 1.

10. United Nations. Transforming Our World: The 2030 Agenda for Sustainable Development; United Nations: New York, NY, USA, 2015.

11. Heidbreder, L.M.; Bablok, I.; Drews, S.; Menzel, C. Tackling the plastic problem. A review on perceptions, behaviors, and interventions. Sci. Total Environ. 2019, 668, 1077-1093. [CrossRef]

12. Eurostat. Packaging Waste Statistics; European Commission: Luxembourg, 2020.

13. Schüler, K. Aufkommen Und Verwertung von Verpackungsabfällen in Deutschland Im Jahr 2018; Texte 166/2020; Umweltbundesamt (UBA): Dessau-Roßlau, Germany, 2020.

14. Geiger, J.L.; Steg, L.; van der Werff, E.; Ünal, A.B. A Meta-analysis of factors related to recycling. J. Environ. Psychol. 2019, 64, 78-97. [CrossRef]

15. Barr, S. Factors influencing environmental attitudes and behaviors: A UK case study of household waste management. Environ. Behav. 2007, 39, 435-473. [CrossRef]

16. Corral-Verdugo, V. Situational and personal determinants of waste control practices in Northern Mexico: A study of reuse and recycling behaviors. Resour. Conserv. Recycl. 2003, 39, 265-281. [CrossRef]

17. Cox, J.; Giorgi, S.; Sharp, V.; Strange, K.; Wilson, D.C.; Blakey, N. Household waste prevention-A review of evidence. Waste Manag. Res. 2010, 28, 193-219. [CrossRef]

18. Kurisu, K.H.; Bortoleto, A.P. Comparison of waste prevention behaviors among three Japanese megacity regions in the context of local measures and socio-demographics. Waste Manag. 2011, 31, 1441-1449. [CrossRef] [PubMed]

19. Whitmarsh, L.E.; Haggar, P.; Thomas, M. Waste reduction behaviors at home, at work, and on holiday: What influences behavioral consistency across contexts? Front. Psychol. 2018, 9, 2447. [CrossRef] [PubMed]

20. Gillilan, S.; Werner, C.M.; Olson, L.; Adams, D. Teaching the concept of precycling: A campaign and evaluation. J. Environ. Educ. 1996, 28, 11-18. [CrossRef]

21. O'Rorke, M. Precycling: A step-by-step plan to market source reduction to consumers. In Proceedings of the Recycling '89 and Beyond, the Annual Conference of the National Recycling Coalition, Charlotte, NC, USA, 31 October-3 November 1989; pp. 77-80.

22. Greyson, J. An economic instrument for zero waste, economic growth and sustainability. J. Clean. Prod. 2007, 15, 1382-1390. [CrossRef]

23. Klug, K. Precycling: Bevor der müll entsteht. In Vom Nischentrend zum Lebensstil; Springer Fachmedien Wiesbaden: Wiesbaden, Germany, 2018; pp. 59-68.

24. Fritsche, I.; Barth, M.; Jugert, P.; Masson, T.; Reese, G. A social identity model of pro-environmental action (SIMPEA). Psychol. Rev. 2018, 125, 245-269. [CrossRef]

25. Tajfel, H.; Turner, J.C. An integrative theory of intergroup conflict. In The Social Psychology of Intergroup Relations; Brooks/Cole: Monterey, CA, USA, 1979; pp. 33-37.

26. Ajzen, I. The theory of planned behavior. Organ. Behav. Hum. Decis. Proc. 1991, 50, 179-211. [CrossRef]

27. Ertz, M.; Huang, R.; Jo, M.-S.; Karakas, F.; Sarigöllü, E. From single-use to multi-use: Study of consumers' behavior toward consumption of reusable containers. J. Environ. Manag. 2017, 193, 334-344. [CrossRef]

28. Heidbreder, L.M. The influence of morality on private and political behaviour involving a reduction in plastic use. In Green Ways_Perspectives of Environmental Psychology Research; Reese, G., Römpke, A.-K., Mues, A.W., Bockmühl, K., Eds.; BfN-Skripten: Bonn, Germany, 2019; Volume 529, pp. 65-78.

29. Heidbreder, L.M.; Schmitt, M. Fasting plastic: An intervention study to break habits of plastic consumption. PsyEcology 2020, 11, 1-23. [CrossRef]

30. Kaplan Mintz, K.; Henn, L.; Park, J.; Kurman, J. What predicts household waste management behaviors? Culture and type of behavior as moderators. Resour. Conserv. Recycl. 2019, 145, 11-18. [CrossRef]

31. Kröger, M.; Wittwer, A.; Pape, J. Unverpackt einkaufen: Mit neuen routinen aus der nische? Ökologisches Wirtsch. Fachz. 2018, $33,46-50$.

32. Linn, N.; Vining, J.; Feeley, P.A. Toward a sustainable society: Waste minimization through environmentally conscious consuming. J. Appl. Soc. Pyschol. 1994, 24, 1550-1572. [CrossRef] 
33. Tonglet, M.; Phillips, P.S.; Bates, M.P. Determining the drivers for householder pro-environmental behaviour: Waste minimisation compared to recycling. Resour. Conserv. Recycl. 2004, 42, 27-48. [CrossRef]

34. Tucker, P.; Douglas, P. Understanding Household Waste Prevention Behavior. Final Report; University of Paisley Environmental Technology Group: Paisley, UK, 2007.

35. Tröger, J.; Reese, G. Talkin' bout a revolution: An expert interview study exploring barriers and keys to engender change towards societal sufficiency orientation. Sustain. Sci. 2021. [CrossRef]

36. Fuentes, C.; Enarsson, P.; Kristoffersson, L. Unpacking package free shopping: Alternative retailing and the reinvention of the practice of shopping. J. Retail. Consum. Serv. 2019, 50, 258-265. [CrossRef]

37. Halkier, B. Social Interaction as key to understanding the intertwining of routinized and culturally contested consumption. Cult. Sociol. 2020, 14, 399-416. [CrossRef]

38. Valentine, G. Eating in: Home, consumption and identity. Soc. Rev. 1999, 47, 491-524. [CrossRef]

39. Jorgensen, B.S.; Boulet, M.; Hoek, A.C. A level-of-analysis issue in resource consumption and environmental behavior research: A theoretical and empirical contradiction. J. Environ. Manag. 2020, 260, 110154. [CrossRef]

40. Graham-Rowe, E.; Jessop, D.C.; Sparks, P. Predicting household food waste reduction using an extended theory of planned behaviour. Resour. Conserv. Recycl. 2015, 101, 194-202. [CrossRef]

41. Defra. Household Waste Prevention Evidence Review: L3 M3-9 (T)—Small Group Approaches to Behviour Change; WR1204; Defra: London, UK, 2009; pp. 1-9.

42. Staats, H.; Harland, P.; Wilke, H.A.M. Effecting durable change: A team approach to improve environmental behavior in the household. Environ. Behav. 2004, 36, 341-367. [CrossRef]

43. Bekin, C.; Carrigan, M.; Szmigin, I. Beyond recycling: ‘Commons-friendly' waste reduction at new consumption communities. J. Cust. Behav. 2007, 6, 271-286. [CrossRef]

44. Abrahamse, W.; Steg, L. Social influence approaches to encourage resource conservation. A meta-analysis. Glob. Environ. Chang. 2013, 23, 1773-1785. [CrossRef]

45. Nisa, C.F.; Bélanger, J.J.; Schumpe, B.M.; Faller, D.G. Meta-analysis of randomised controlled trials testing behavioural interventions to promote household action on climate change. Nat. Commun. 2019, 10, 4545. [CrossRef] [PubMed]

46. Bergquist, M.; Nilsson, A.; Schultz, W.P. A meta-analysis of field-experiments using social norms to promote pro-environmental behaviors. Glob. Environ. Chang. 2019, 59, 101941. [CrossRef]

47. Reese, G.; Junge, E. Keep on rockin' in a (plastic-)free world: Collective efficacy and pro-environmental intentions as a function of task difficulty. Sustainability 2017, 9, 200. [CrossRef]

48. Turner, J.C.; Hogg, M.A.; Oakes, P.J.; Reicher, S.D.; Wetherell, M.S. Rediscovering the social group: A self- categorization theory. Contemp. Sociol. 1987, 18, 645. [CrossRef]

49. Fielding, K.S.; Hornsey, M.J. A social identity analysis of climate change and environmental attitudes and behaviors: Insights and opportunities. Front. Psychol. 2016, 7, 121. [CrossRef]

50. Postmes, T.; Haslam, S.A.; Swaab, R.I. Social influence in small groups: An interactive model of social identity formation. Eur. Rev. Soc. Psychol. 2005, 16, 1-42. [CrossRef]

51. Thomas, E.F.; McGarty, C.; Mavor, K. Group interaction as the crucible of social identity formation: A glimpse at the foundations of social identities for collective action. Group Process. Intergroup Relat. 2016, 19, 137-151. [CrossRef]

52. Forsyth, D.R. Group Dynamics, 5th ed.; Wadsworth, Cengage Learning: San Francisco, CA, USA, 2010.

53. Cialdini, R.B.; Reno, R.R.; Kallgren, C.A. A focus theory of normative conduct: Recycling the concept of norms to reduce littering in public places. J. Pers. Soc. Psychol. 1990, 58, 1015-1026. [CrossRef]

54. Bandura, A. Exercise of human agency through collective efficacy. Curr. Dir. Psychol. Sci. 2000, 9, 75-78. [CrossRef]

55. Hamann, K.R.S.; Reese, G. My influence on the world (of others): Goal efficacy beliefs and efficacy affect predict private, public, and activist pro-environmental behavior. J. Soc. Issues 2020, 76, 35-53. [CrossRef]

56. Chappells, H.; Medd, W.; Shove, E. Disruption and change: Drought and the inconspicuous dynamics of garden lives. Soc. Cult. Geogr. 2011, 12, 701-715. [CrossRef]

57. Bolger, N.; Davis, A.; Rafaeli, E. Diary methods: Capturing life as it is lived. Annu. Rev. Psychol. 2003, 54, 579-616. [CrossRef] [PubMed]

58. Harper, D. Talking about pictures: A case for photo elicitation. Vis. Stud. 2002, 17, 13-26. [CrossRef]

59. Zimmerman, D.H.; Wieder, D.L. The diary: Diary-interview method. Urban. Life 1977, 5, 479-498. [CrossRef]

60. ATLAS.Ti; ATLAS.ti Scientific Software Development GmbH: Berlin, Germany, 2020.

61. Mayring, P. Qualitative Inhaltsanalyse: Grundlagen und Techniken, 12nd ed.; Beltz Verlag: Weinheim, Germany, 2015.

62. Barr, S.; Gilg, A.W.; Ford, N.J. Differences between household waste reduction, reuse and recycling behaviour: A study of reported behaviours, intentions and explanatory variables. Environ. Waste Manag. 2001, 4, 69-82.

63. Bartels, J.; Hoogendam, K. The role of social identity and attitudes toward sustainability brands in buying behaviors for organic products. J. Brand Manag. 2011, 18, 697-708. [CrossRef]

64. Fielding, K.S.; McDonald, R.; Louis, W.R. Theory of planned behaviour, identity and intentions to engage in environmental activism. J. Environ. Psychol. 2008, 28, 318-326. [CrossRef]

65. Sloot, D.; Jans, L.; Steg, L. Can community energy initiatives motivate sustainable energy behaviours? The Role of initiative involvement and personal pro-environmental motivation. J. Environ. Psychol. 2018, 57, 99-106. [CrossRef] 
66. Udall, A.M.; Groot, J.I.M.; Jong, S.B.; Shankar, A. How do i see myself? A systematic review of identities in pro-environmental behaviour research. J. Consum. Behav. 2020, 19, 108-141. [CrossRef]

67. Thomas, E.F.; McGarty, C.; Mavor, K.I. Aligning identities, emotions, and beliefs to create commitment to sustainable social and political action. Pers. Soc. Psychol. Rev. 2009, 13, 194-218. [CrossRef] [PubMed]

68. van Zomeren, M.; Postmes, T.; Spears, R. Toward an integrative social identity model of collective action: A quantitative research synthesis of three socio-psychological perspectives. Psychol. Bull. 2008, 134, 504-535. [CrossRef] [PubMed]

69. Detzel, A.; Kauertz, B.; Grahl, B.; Heinisch, J. Prüfung Und Aktualisierung Der Ökobilanzen Für Getränkeverpackungen; TEXTE 19/2016; Umweltbundesamt (UBA): Dessau-Roßlau, Germany, 2016.

70. Reese, G.; Hamann, K.R.S.; Heidbreder, L.M.; Loy, L.S.; Menzel, C.; Neubert, S.; Tröger, J.; Wullenkord, M.C. SARS-Cov-2 and environmental protection: A collective psychology agenda for environmental psychology research. J. Environ. Psychol. 2020, 70, 101444. [CrossRef] [PubMed]

71. van Zomeren, M.; Saguy, T.; Schellhaas, F.M.H. Believing in "making a difference" to collective efforts: Participative efficacy beliefs as a unique predictor of collective action. Group Process. Intergroup Relat. 2013, 16, 618-634. [CrossRef]

72. Vesely, S.; Masson, T.; Chokrai, P.; Becker, A.; Fritsche, I.; Klöckner, C.; Tiberio, L.; Carrus, G.; Panno, A. Climate change action as a project of identity: Eight meta-analyses. in press.

73. Whitmarsh, L.; O'Neill, S. Green identity, green living? The role of pro-environmental self-identity in determining consistency across diverse pro-environmental behaviours. J. Environ. Psychol. 2010, 30, 305-314. [CrossRef]

74. Schultz, T.; Fielding, K. The common in-group identity model enhances communication about recycled water. J. Environ. Psychol. 2014, 40, 296-305. [CrossRef]

75. Nolan, J.M.; Schultz, P.W.; Cialdini, R.B.; Goldstein, N.J.; Griskevicius, V. Normative social influence is underdetected. Pers. Soc. Psychol. Bull. 2008, 34, 913-923. [CrossRef]

76. Rabinovich, A.; Morton, T.A.; Postmes, T.; Verplanken, B. Collective self and individual choice: The effects of inter-group comparative context on environmental values and behaviour: Inter-group comparison affects individual values and behaviour. Br. J. Soc. Psychol. 2012, 51, 551-569. [CrossRef]

77. Schultz, P.W.; Nolan, J.M.; Cialdini, R.B.; Goldstein, N.J.; Griskevicius, V. The constructive, destructive, and reconstructive power of social norms. Psychol. Sci. 2007, 18, 429-434. [CrossRef]

78. Süßbauer, E.; Schäfer, M. Greening the workplace: Conceptualising workplaces as settings for enabling sustainable consumption. Int. J. Innov. Sustain. Dev. 2018, 12, 327. [CrossRef]

79. Seebauer, S.; Fleiß, J.; Schweighart, M. A household is not a person: Consistency of pro-environmental behavior in adult couples and the accuracy of proxy-reports. Environ. Behav. 2017, 49, 603-637. [CrossRef] [PubMed] 